\title{
Uma Implementação de Sockets sobre Fast Messages em Redes Myrinet
}

\author{
Luís Gustavo Covino
}

Orientador: Prof. Dr. Onofre Trindade Júnior

Dissertação apresentada ao Instituto de Ciências Matemáticas e de Computação - ICMC-USP, como parte dos requisitos para obtenção do título de Mestre em Ciências - Área: Ciências de Computação e Matemática Computacional.

São Carlos

Novembro/1999 


\section{Resumo}

O aumento da complexidade dos problemas resolvidos por computador tem tornado importante a utilização de processamento paralelo. O uso de computadores convencionais conectados por redes de comunicação de alta velocidade é uma alternativa viável e de baixo custo em relação aos MPPs (Massively Parallel Processors) em aplicações que demandam alto poder computacional. Uma biblioteca de alto nível muito utilizada para a programação paralela, que utiliza o paradigma de passagem de mensagens, é o PVM (Parallel Virtual Machine). PVM utiliza TCP/IP (sockets) para comunicação entre os processos paralelos. Este trabalho de mestrado demonstra que pode-se atingir um desempenho maior em comunicação se Fast Messages for utilizado em vez de TCP/IP no PVM. Uma biblioteca, denominada Sock2Fm, que utiliza a semântica de sockets e usa Fast Messages em baixo nível, foi desenvolvida e foram realizados testes para aferição de seu desempenho. Essa biblioteca também pode ser utilizada diretamente para troca de mensagens na rede, sendo mais adequada para o programador acostumado com sockets do que com o uso das primitivas de Fast Messages. Testes mostram que Sock2Fm apresenta um desempenho melhor que TCP/IP para mensagens maiores que 250 bytes ( $79 \%$ melhor para alguns tamanhos de pacotes).Também foi aferido o desempenho de PVM sobre Ethernet a $10 \mathrm{Mbps}, 100 \mathrm{Mbps}$ e sobre Myrinet com TCP/IP para comparação dos resultados. 


\section{Abstract}

Conventional computers connected by high-speed communication networks present a very low cost alternative to the MPPs (Massively Parallel Processors) for applications that demand high computing power. A widespread communication system that uses the message-passing paradigm is PVM (Parallel Virtual Machine). PVM uses TCP/IP for interprocess communication. This work shows that it is possible to achieve a better performance with PVM if Fast Messages is used instead of TCP/IP. A library, called Sock2Fm, that has the semantics of sockets and uses Fast Messages in a lower level, was developed and had its performance measured. Programmers that use the sockets API (APplication Interface) can make calls directly to the Sock2Fm functions, avoiding the use of the less known Fast Messages interface. Tests show that Sock2Fm presents a better perfomance than TCP/IP for messages bigger than 250 bytes ( $79 \%$ better for some packet sizes). The performance of PVM was also measured for $10 \mathrm{Mbps}$ Ethernet, $100 \mathrm{Mbps}$ Ethernet and Myrinet with TCP/IP. The results were analyzed and compared with the performance of Sock2Fm. 
Aos meus pais,

Nilto e Lurdes 


\section{Agradecimentos}

Ao meu orientador, Prof. Dr. Onofre Trindade Júnior, pelos sábios ensinamentos, pelo apoio e pelas oportunidades que contribuíram para minha formação.

Aos professores do Instituto de Ciências Matemáticas e de Computação, em especial aos que em algum momento na graduação me orientaram, professores Paulo César Masiero e Edson dos Santos Moreira.

A todos os colegas dos laboratórios LCAD, Intermídia e Labic, entre outros. Aprendemos muito juntos.

Aos amigos que me acompanharam na vida acadêmica, que não citarei os nomes por serem tantos e por ser injusto se o nome de algum faltar. Todos foram muito importantes.

Ao pessoal das seções de graduação e pós-graduação, sempre pronto a oferecer ajuda quando precisamos.

À minha namorada, Adriana, por estar sempre presente em todos os momentos de minha vida.

Ao CNPq e à Fapesp, pelo apoio ao projeto. 


\section{Índice de Figuras}

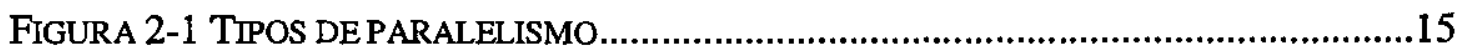

FIGURA 2-1 ARQUTIETURA MIMD COM MEMÓRIA COMPARTILHADA..........................23

FIGURA 2-2 ARQUTTETURA MIMD COM MEMÓRIA DISTRIBUIDA..................................24

FIGURA 2-3 TOPOLOGIAS ESTÁTICAS PARA REDES DE COMUNICAÇÃO ..........................27

FIGURA 2-4 TOPOLOGIAS DINÂMICAS PARA REDES DE COMUNICAÇÃO ........................29

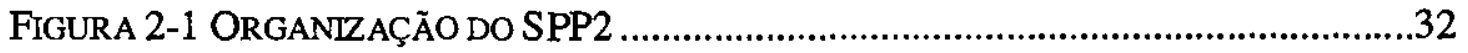

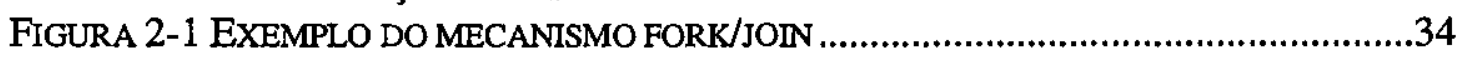

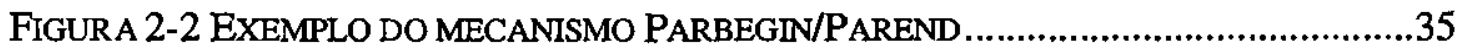

FIGURA 2-1 MECANISMOS PARA COMUNICAÇÃO ENTRE PROCESSOS.............................37

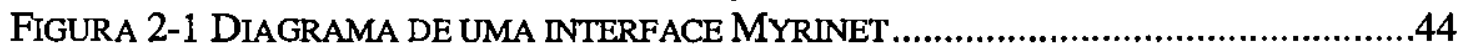

FIGURA 3-1 DESEMPENHO COMPARATIVO ENTREA API FM E A API MYRINET .............49

FIGURA 3-2 COMPARAÇÃO DE DESEMPENHO DE MPI ENTRE O IBM SP2, CRAY T3D E

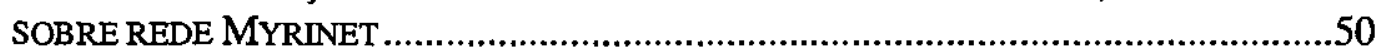

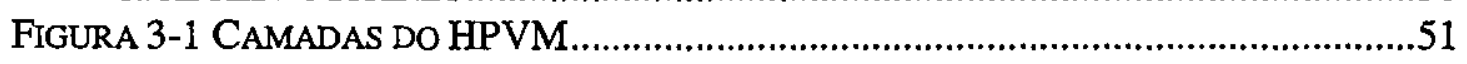

FIGURA 3-1 CAMADAS DO SISTEMA DE COMUNICAÇÃO COM SOCK2FM.........................55

FIGURA 3-2 EXEMPLO DE CONEXÃO PARA PROTOCOLO CONECTADO TIPO TCP .............56

FIGURA 4-1 DESEMPENHO COMPARATIVO DE TCP/IP E SOCK2FM EM REDE MYRINET ..63

FIGURA 4-1 TAXA DE TRANSFERÊNCIA PARA SOCKETS PADRÃO ..................................65

FIGURA 4 2 TAXA DE PVM PARA PACOTES ENTRE 10 E 500 BYTES ............................67

FIGURA 4-3 TAXA DE PVM PARA PACOTES ENTRE 1.000 E 50.000 BYTES ...................68 


\section{Índice}

1. INTRODUÇÃ

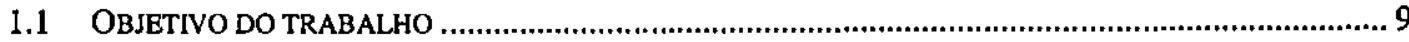

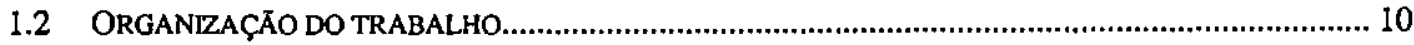

2. PROCESSAMENTO PARALELO

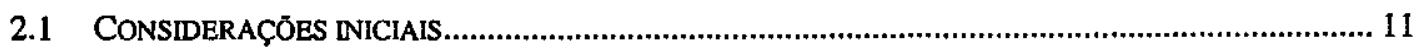

2.2 INTRODUÇÃO AO PROCESSAMENTO PARALELO........................................................................ 11

2.2.1 Paralelismo, concorrência e processamento seqüencial...............................................13

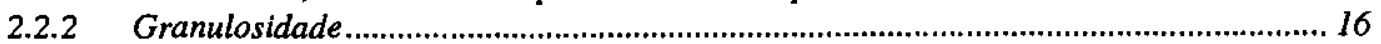

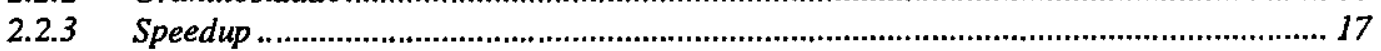

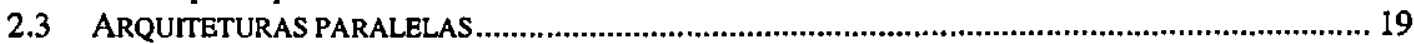

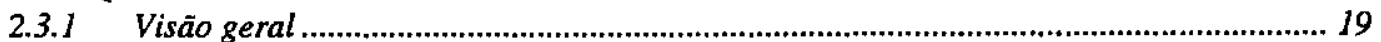

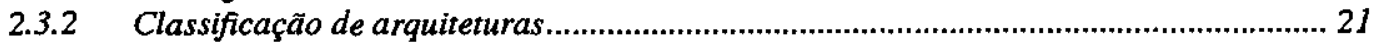

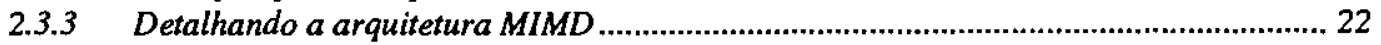

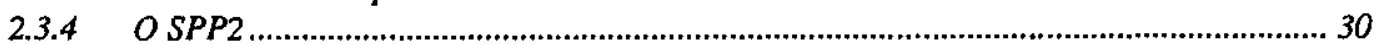

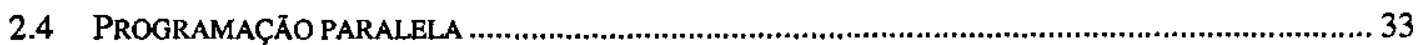

2.4.1 Iniciando e terminando a execução de sub-tarefas ......................................................... 33

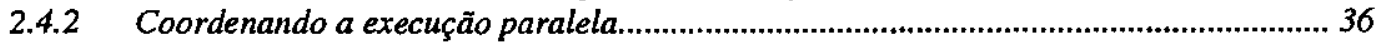

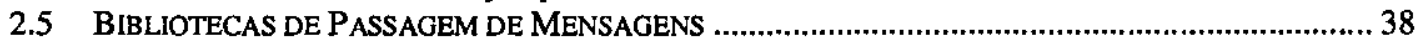

2.5.1 PVM

2.5.2 MPI

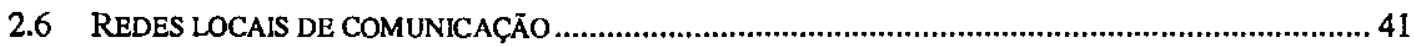

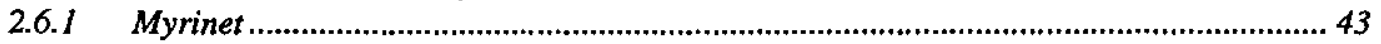

2.7 MÉTODO PARA ANÁLISE DE SISTEMAS DE COMUNICAÇĀO .......................................................4 45

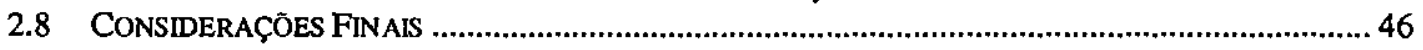

3. FAST MESSAGES E A BIBLIOTECA SOCK2FM …........................................................4 47

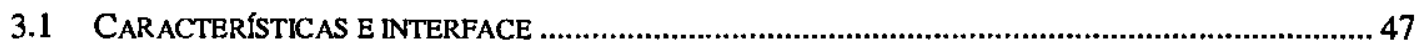

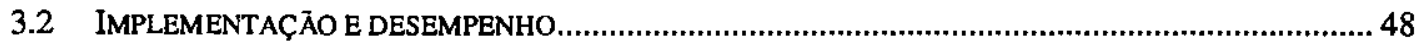

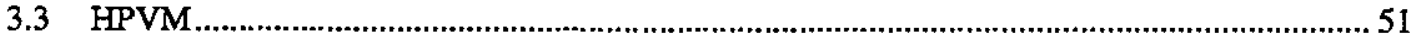

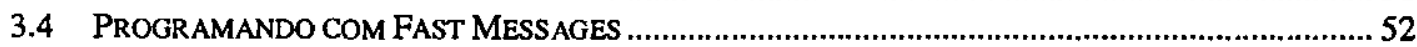

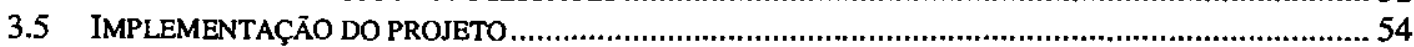

3.6 OTIMIZAÇŌES PARA MAIORES GANHOS DE DESEMPENHO …................................................ 57

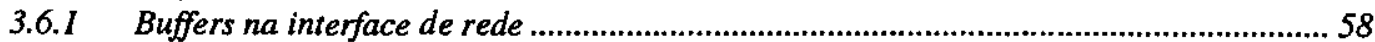

3.6.2 Armazenamento de mensagens em listas encadeadas ......................................................5 59

3.6.3 Recebimento de mensagens diretamente em espaço do usuário .....................................5 59

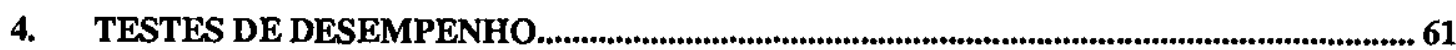

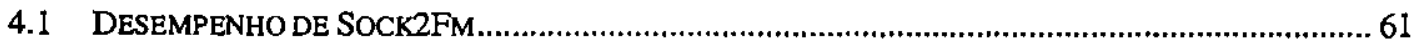

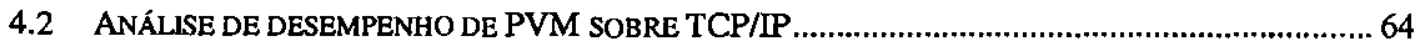

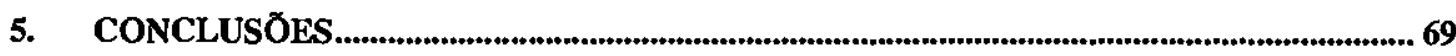

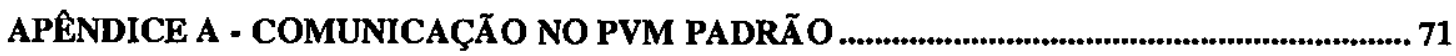

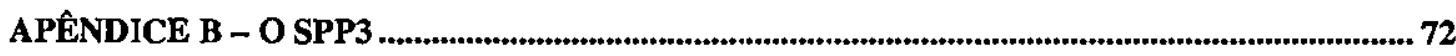

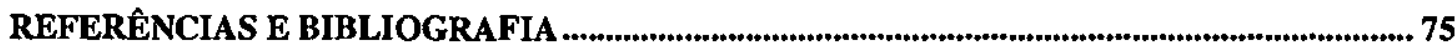




\section{Introdução}

A solução para problemas que demandam grande poder computacional muitas vezes somente pode ser obtida com o uso de computação paralela. Tais problemas, como as simulações climáticas, por exemplo, geralmente envolvem muitos cálculos e necessitam de processamento de alto desempenho para que possam ser feitas com a precisão e velocidade necessárias.

As máquinas mais usadas nos dias de hoje para suprir essa necessidade de desempenho são os chamados MPPs (Massively Parallel Processors) [HWA93], que são máquinas com muitos processadores seqüenciais ligados a uma quantidade muito grande (Gigabytes) de memória [GEI94]. Uma alternativa aos MPPs é o uso de redes de computadores (Networks of Workstations) [PAK95]. Nas redes de computadores, computadores independentes ligados por redes de comunicação são utilizados para formar uma máquina paralela virtual e trabalhar em conjunto na solução de problemas. Como vantagens dessas redes em relação aos MPPs pode-se citar o baixo custo e uma maior quantidade de software disponível.

Comum a essas duas abordagens está o paradigma de Passagem de Mensagens (Message-Passing) [SNI96]. No processamento paralelo, dados devem ser trocados entre os processos que cooperam entre si para a realização da tarefa. O método mais utilizado para essa troca é o envio e o recebimento de mensagens pelos processos, seja através de memória compartilhada ou através de uma rede de comunicação. PVM (Parallel Virtual Machine) [GEI94] e MPI (Message Passing Interface) [SNI96] estão entre as bibliotecas mais usadas atualmente para a passagem de mensagens entre processos paralelos, estando disponíveis para várias plataformas comerciais.

Obter uma comunicação entre processadores rápida e eficiente é o maior desafio na síntese de máquinas paralelas utilizando-se redes de computadores. A plataforma de comunicação mais tradicional é o uso do sistema PVM sobre TCP/IP em redes Ethernet a $10 \mathrm{Mbps}$. Para melhorar o desempenho da comunicação nessa classe de sistemas, foi desenvolvido na Universidade de Illinois o protocolo Fast 
Messages (FM) para redes Myrinet. Uma das vantagens do FM em relação ao TCP/IP é o menor overhead de comunicação que o FM introduz.

O objetivo do sistema Fast Messages é otimizar a camada de software de troca de mensagens que reside entre o hardware e os serviços de comunicação de baixo nível. Utilizando a rede Myrinet, o FM permite um desempenho da comunicação em redes de estações de trabalho comparável com o dos MPPs a um custo relativamente muito menor [PAK95].

Uma versão de MPI foi implementada sobre o sistema Fast Messages, tendo apresentado alto desempenho em uma rede de computadores da Sun Microsystems (SparcStations) [LAU96].

\subsection{Objetivo do trabalho}

No Laboratório de Computação de Alto Desempenho (LCAD) do ICMSC USP foi projetada uma máquina paralela, denominada SPP2, baseada em hardware de computadores pessoais conectados por uma rede de comunicação de alta velocidade [TRI95a]. Os computadores, ou nós, são baseados em processadores Intel Pentium executando o sistema operacional Linux. A rede de alta velocidade originalmente planejada para conectar os nós seria uma rede paralela de oito bits Myricom Myrinet [MYR98]. Essa rede foi instalada de fato na versão mais recente da máquina paralela, a SPP3.

Neste trabalho mostra-se que é possível atingir um desempenho elevado de comunicação utilizando-se PVM sobre Fast Messages ao invés de PVM sobre TCP/IP e sockets. É mostrado que o TCP/IP não é o mecanismo de comunicação mais indicado para a rede Myrinet, pois não se consegue atingir desempenho compatível com a velocidade física do hardware da rede.

Para isso, foi desenvolvida uma biblioteca que usa Fast Messages para comunicação em baixo nível e simula a semântica de sockets. Com essa biblioteca pode-se adaptar facilmente programas que usam TCP/IP para usar Fast Messages e 
apresentar ganhos de desempenho na velocidade de transmissão, como é o caso das implementações padrão da biblioteca PVM.

Para se mostrar que TCP/IP não aproveita todo o potencial da rede Myrinet foram feitos testes de desempenho comparativos das plataformas PVM-TCP/IPEthernet a $10 \mathrm{Mbps}$, PVM-TCP/IP-Ethernet a $100 \mathrm{Mbps}$ e PVM-TCP/IP-Myrinet.

\subsection{Organização do trabalho}

O capítulo 2 aborda os principais tópicos que envolvem o processamento paralelo, desde as arquiteturas mais usuais até aspectos de programação, situando-se a máquina SPP2 nesse contexto. As técnicas utilizadas para medição de desempenho em sistemas de comunicação também são apresentadas.

O capítulo 3 apresenta o desenvolvimento da biblioteca Sock2Fm e também o sistema de troca de mensagens Fast Messages. São discutidos sua implementação na rede de alta velocidade Myrinet e os aspectos que justificam os níveis elevados de desempenho apresentados.

O capítulo 4 é reservado para a apresentação e discussão dos resultados de desempenho de comunicação medidos para Sock2Fm e PVM nas diversas configurações da plataforma de teste.

O capítulo 5 apresenta as conclusões finais deste trabalho. 


\section{Processamento Paralelo}

\subsection{Considerações iniciais}

Neste capítulo são revistos os diversos tópicos necessários para 0 desenvolvimento deste trabalho. Neste sentido, na seção 2.2 são apresentadas as características básicas do processamento paralelo. Na seção 2.3 é feita uma descrição das arquiteturas paralelas e da máquina SPP2, desenvolvida no LCAD-USP. Os modelos para programação paralela e os mecanismos para se obter o controle de ativação, de término, de sincronização e a comunicação entre processos em diferentes arquiteturas são descritos na seção 2.4. Na seção 2.5 são apresentados os sistemas PVM e MPI, as duas bibliotecas de passagem de mensảgens mais usadas atualmente.

As redes de comunicação mais comuns que podem integrar o sistema de comunicação de uma máquina paralela baseada em redes de computadores, em especial a Myrinet, são apresentadas na seção 2.6. Na seção 2.7 são apresentados os parâmetros mais importantes para se determinar o desempenho de uma rede de comunicação de dados. Finalmente, na seção 2.8 são apresentadas as considerações finais deste capítulo.

\subsection{Introdução ao processamento paralelo}

O processamento paralelo pode ser definido como o trabalho realizado por um conjunto de elementos de processamento (ou processadores) que trabalham coletivamente, cooperando uns com os outros, na solução de um problema computacional [FOS95]. Para isso, é aproveitada a possível independência de eventos existente no que seria uma solução seqüencial do problema.

A grande vantagem do processamento paralelo é o ganho de desempenho que ele apresenta em relação ao processamento sequencial tradicional introduzido pela clássica arquitetura de von Neumann. Determinadas aplicações possuem um 
paralelismo intrínseco em suas tarefas, facilmente identificado, e essas aplicações podem gerar resultados em tempos muitíssimas vezes menores do que a computação seqüencial.

Em 1967 foi desenvolvido na universidade americana de Illinois aquele que é considerado efetivamente o primeiro computador paralelo da história. O ILLIAC IV, como é chamado, é composto por 64 processadores que possuem cada um 16 Kbytes de memória, totalizando 1 Mbytes na máquina toda. Mesmo contendo apenas $25 \%$ do número de processadores inicialmente previsto, seu custo na época atingiu 31 milhões de dólares, quatro vezes mais do que era esperado [ALM94]. O ILLIAC IV operou na NASA até o ano de 1981, quando foi substituído por um CRAY-I. Ele foi usado principalmente para a resolução de equações de fluxo aerodinâmico e simulações climáticas.

Algumas aplicações, como as que demandam grande quantidade de cálculos, necessitam de máquinas com alto desempenho de processamento para produzirem resultados úteis. De nada adianta, por exemplo, realizar-se simulações climáticas com previsão de dois dias se os cálculos demorarem mais tempo que isso. Nesse caso, o resultado da previsão seria para um dia que já passou. Por mais avançadas e rápidas que as máquinas sequienciais têm se tornado, elas são mais lentas do que as máquinas paralelas.

Mesmo que em alguns anos um único processador possa atingir a potência computacional da máquina paralela mais veloz de hoje, sempre será possível construir máquinas paralelas baseadas nesse processador, multiplicando assim a capacidade de processamento. Um fator favorável ao processamento paralelo é que a tecnologia de processamento sequiencial tem um limite físico a ser atingido: a velocidade da luz. Mesmo com chips que futuramente possam usar a transmissão de luz na sua arquitetura interna ao invés de corrente elétrica, que é mais lenta, a velocidade da luz será um fator limitante para a evolução da potência computacional dos processadores.

Mas será que nesse ponto os computadores seqüenciais não conseguirão satisfazer as necessidades computacionais que a sua era exigir? Freqüentemente temse a impressão que os computadores se tornaram rápidos o suficiente para as aplicações existentes, ou que no ritmo que a evolução dos processadores caminha, logo teremos poder computacional de sobra para essas aplicações. Entretanto, quando 
uma tecnologia satisfaz as aplicações existentes em um determinado momento, novas aplicações que são motivadas por aquela tecnologia surgem e fazem com que seja necessário o desenvolvimento de nova tecnologia. A constante evolução é então preponderante para o desenvolvimento contínuo da ciência.

Os processadores sequienciais mais poderosos da atualidade não são simplesmente seqüenciais. Esses processadores conseguem atingir grande desempenho porque entre outras coisas eles utilizam técnicas de pipeline, múltiplas unidades de execução em paralelo, execução fora de ordem e especulativa de instruções. Com essas técnicas se consegue executar mais instruções por ciclo de clock da máquina e assim aumentar o desempenho. $O$ programador das linguagens de alto nível não fica ciente do paralelismo que está ocorrendo. Geralmente os bons compiladores é que fazem pequenos ajustes no código executável gerado para esses processadores para se obter um maior aproveitamento dos recursos existentes.

O processamento paralelo tem sido ligado tradicionalmente a aplicações que envolvem cálculo numérico tais como simulações de clima, fluidos, reações químicas, circuitos eletrônicos, peças mecânicas, etc. Atualmente uma nova gama de aplicações, como as relacionadas à multimídia, pode se beneficiar das vantagens do processamento paralelo. Exemplos comuns incluem a realidade virtual e a compressão de vídeo em tempo real. A realidade virtual precisa de grande poder de processamento para gerar imagens realistas de ambientes tridimensionais em tempo real. A compressão de vídeo para a transmissão em redes de computadores, com alta qualidade de imagem e som como exige o padrão HDTV, por exemplo, exige a manipulação de grande quantidade de dados em tempo real. Essas novas aplicações irão aproximar o processamento paralelo do cotidiano da computação.

\subsubsection{Paralelismo, concorrência e processamento seqüencial}

Os termos concorrência e paralelismo são muitas vezes usados com o mesmo significado, mas eles realmente dão nome a conceitos diferentes. Pode-se defini-los da seguinte forma: 
- Concorrência: Dois ou mais eventos estão em execução ao mesmo tempo, podendo eventualmente compartilhar uma única unidade de processamento (time-sharing);

- Paralelismo: Dois ou mais eventos estão em execução ao mesmo tempo, cada um em uma unidade de processamento separada.

Todo processamento paralelo é concorrente, mas nem todo processamento concorrente é realmente paralelo. Paralelismo é uma forma de processamento concorrente. Já o processamento seqüencial ocorre quando um evento só pode iniciar após o término de outro. Máquinas com apenas 1 processador podem apresentar comportamento tanto concorrente quanto sequencial, dependendo do sistema operacional que a máquina executa. Os sistemas operacionais chamados de "multitarefas" têm a capacidade de executar mais do que um processo por vez de forma concorrente. Eles dividem o uso do processador, e essa divisão é uma tarefa que fica a cargo do sistema de escalonamento do sistema operacional.

Em alguns computadores que possuem mais que um processador, seus sistemas operacionais podem realizar o time-sharing em cada um dos processadores. O sistema operacional UNIX apresenta essa característica em algumas plataformas, como as máquinas com múltiplos processadores da Sun que executam as versões Solaris do UNIX. Com isso, tem-se um sistema misto entre o paralelismo real e o time-sharing. A Figura 2-1 mostra as possíveis formas de processamento concorrente. 


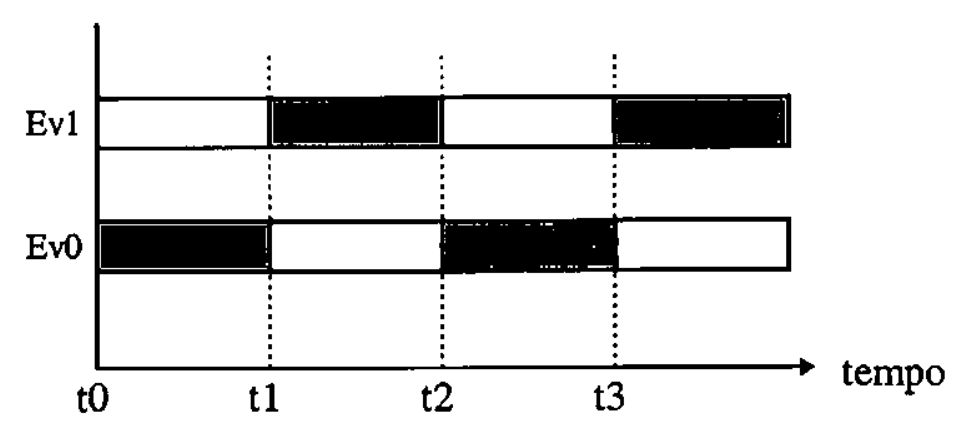

(a)

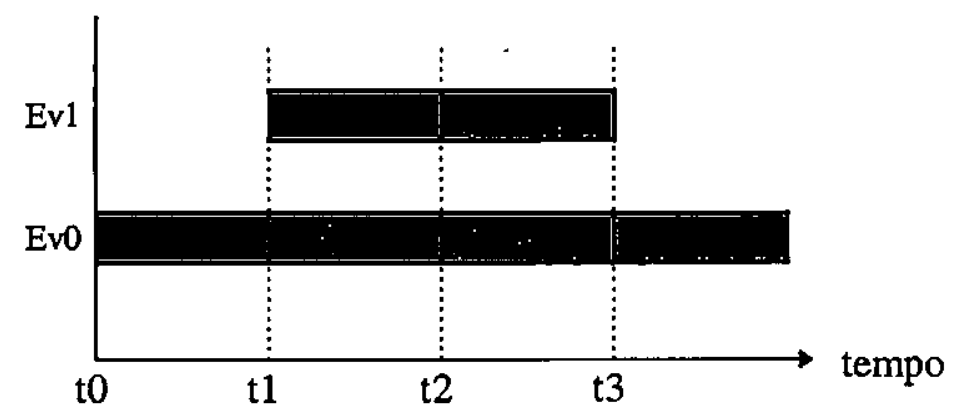

(b)

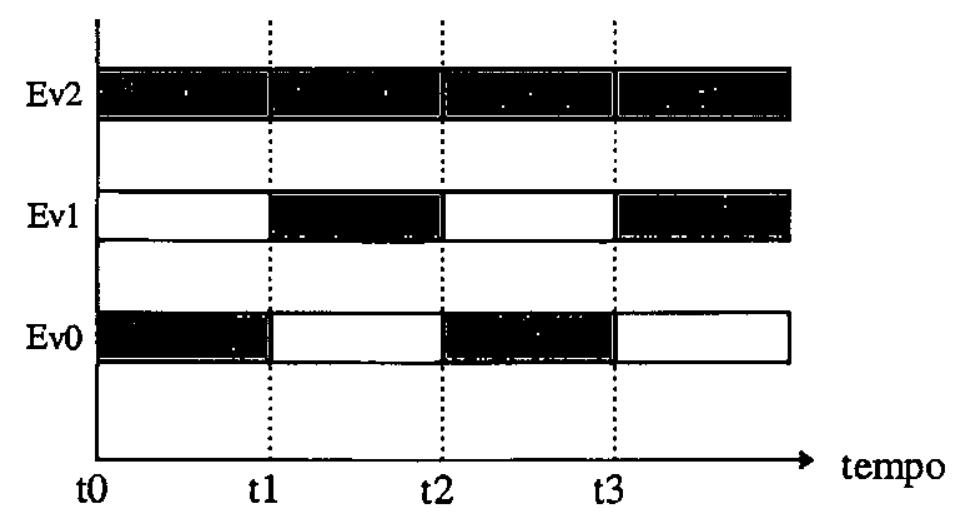

(c)

Figura 2-1 Tipos de paralelismo

Na Figura 2-1 (a), um único processador realiza o time-sharing entre dois processos concorrentes, Ev0 e Ev1. Ev0, por exemplo, está em execução entre os 
tempos t0 e tl e entre t 2 e $\mathrm{t} 3$, enquanto Ev 1 está em modo de espera. A Figura 2-1 (b) mostra a execução paralela de dois processos em dois processadores diferentes, sendo que Evl começa sua execução em t1 e termina em $t 3$, período no qual Ev0 também está em execução. Três processos estão representados na Figura 2-1 (c). Ev2 está em execução em um processador, enquanto dois outros processos, Ev0 e Ev1, compartilham um outro processador.

\subsubsection{Granulosidade}

Para se obter ganhos de desempenho numa aplicação paralela deve-se particionar o problema (tarefa) em diversos processos paralelos para que cada elemento de processamento desempenhe o seu papel na solução. $O$ tamanho de cada processo paralelo determina a "granulosidade" em que o problema foi dividido. Essa granulosidade geralmente é medida em número médio de instruções de cada processo (sub-tarefa) [HWA93]. Um particionamento apropriado tem fator fundamental no ganho de desempenho (ou speedup, descrito na seção seguinte) que o programa paralelo obterá em relação ao que seria uma versão seqüencial da aplicação.

Os processos paralelos precisam se comunicar para trocar dados e informações de sincronização. O overhead introduzido pelo tempo dessa comunicação deve ser mínimo em relação ao tempo de processamento efetivo da computação. A granulosidade deve ser dimensionada segundo esse parâmetro, e ela depende do tipo de arquitetura na qual a aplicação será executada. Se o computador paralelo tiver poucos processadores, uma granulosidade maior é mais apropriada. Nesse caso, uma granulosidade pequena acarretaria num grande overhead de comunicação e os processadores não seriam aproveitados eficientemente. No caso de uma máquina com muitos processadores, uma granulosidade menor tiraria proveito da capacidade de processamento que a soma do poder dos processadores individuais apresenta.

A granulosidade pode ser medida, desde a mais grossa até a mais fina, segundo a seguinte hierarquia [ALM94]:

- Programa: nível mais alto de granulosidade, correspondendo a programas inteiros.

Esse nível é mais indicado para o paralelismo realizado pelos sistemas operacionais 
em máquinas com mais de um processador, aumentando o desempenho na execução de várias aplicações ao mesmo tempo, e não necessariamente o desempenho de uma única aplicação;

- Subrotinas: são os diversos procedimentos que formam um programa;

- Loops: os trechos de código que realizam iterações;

- Comandos: linhas de código;

- Expressões: nível mais próximo das instruções da máquina.

\subsubsection{Speedup}

O ganho de desempenho de uma aplicação paralela em relação a uma versão sequiencial da aplicação é chamado de speedup. O speedup pode ser descrito simplesmente como a fração $\mathrm{Ts} / \mathrm{Tp}$, onde Ts é o tempo de execução serial e Tp é o tempo de execução paralela:

$$
\mathrm{Sp}=\mathrm{Ts} / \mathrm{Tp}
$$

Como as tarefas a serem atribuídas a cada elemento de processamento nas aplicações paralelas dividem seu tempo entre computação e comunicação, Tp pode ser definido como o tempo de comunicação total em $\mathrm{P}$ processadores $\left(\mathrm{Tcomm}_{\mathrm{P}}\right)$ mais um tempo de computação total (Tcompp). Então temos:

$$
\mathrm{Tp}=\mathrm{Tcomp}_{\mathrm{p}}+\mathrm{Tcomm}_{\mathrm{p}}
$$

Numa paralelização ideal, o tempo de processamento de uma aplicação serial seria dividido entre cada elemento processador, sendo que o tempo final seria Ts dividido pelos $\mathrm{P}$ processadores disponíveis. Na maioria das aplicações reais, existem partes de código que não podem ser paralelizadas, devendo ter uma execução seqüencial (Lei de Amdahl [PAT90]). Desta forma, o tempo de computação paralela é dado por

$$
\text { Tcompp }=[\text { Ts }(1-\mathrm{A}) / \mathrm{P}]+\mathrm{Ts} A
$$

onde A é a fração do problema que não pode ser paralelizada. 
Pode-se considerar, para simplificar o modelo, que o tempo de comunicação para $\mathrm{P}$ processadores é proporcional ao tempo de comunicação de 1 processador multiplicado pelo número de processadores. Então:

$\mathrm{Tcomm}_{\mathrm{P}}=\mathrm{P} \mathrm{Tcomm}$

Um parâmetro que representa a qualidade de um sistema de comunicação de uma máquina paralela é a relação entre o tempo de computação e o de comunicação $\left(r_{p}=T s / T c o m m_{p}\right)$. Considerando-se uma tarefa de tamanho fixo, quanto maior for o tempo de computação em relação ao de comunicação, melhor será o sistema de comunicação. Colocando-se em termos de 1 processador, temos que:

$\mathrm{r}_{1}=\mathrm{Ts} / \mathrm{Tcomm}_{1}$

Com os termos acima definidos, pode-se calcular a equação de speedup :

$$
\begin{aligned}
& \mathrm{Sp}=\mathrm{Ts} / \mathrm{Tp} \\
& =\mathrm{Ts} /\left[\text { Tcomp }_{\mathrm{P}}+\text { Tcommp }_{\mathrm{P}}\right] \\
& =\mathrm{Ts} /\left[(\mathrm{Ts}(1-\mathrm{A}) / \mathrm{P})+\mathrm{Ts} \mathrm{A}+\mathrm{P} \mathrm{Tcomm}_{1}\right] \\
& 1 / \mathrm{Sp}=\{(\mathrm{Ts}(1-\mathrm{A}) / \mathrm{P}) / \mathrm{Ts}\}+\{\mathrm{Ts} \mathrm{A} / \mathrm{Ts}\}+\left\{\mathrm{P} \mathrm{Tcomm}_{1} / \mathrm{Ts}\right\} \\
& =(1-\mathrm{A}) / \mathrm{P})+\mathrm{A}+\mathrm{P} / \mathrm{r}_{1} \\
& \left.\mathrm{Sp}=1 /[(1-\mathrm{A}) / \mathrm{P})+\mathrm{A}+\mathrm{P} / \mathrm{r}_{1}\right]
\end{aligned}
$$

Para um $A=0,005$ e 10 processadores, se a relação $r_{1}$ for 20 , ou seja, a computação ocupa 20 vezes mais tempo que a comunicação em 1 processador, o speedup é de 1,65. Com um sistema de comunicação com o dobro de velocidade, a relação $r_{1}$ vai para 40 e o speedup fica em 2,82 . Se a comunicação atingir 10 vezes a velocidade inicial, $r_{1}$ fica em 200 e o speedup atinge 6,47. Pode-se ver assim a importância que um sistema de comunicação eficiente tem no universo das arquiteturas e sistemas de computação paralelos, uma vez que um aumento de 10 vezes na velocidade de comunicação (o que pode ser exemplificado, no caso de uma 
rede local de computadores, pela troca de uma Fast Ethernet por uma Myrinet ou ATM) provocou uma melhora de quase 5 unidades no speedup.

A fórmula teórica para speedup mostra não só a vantagem de uma execução paralela em relação à seqüencial, mas também a vantagem que um sistema de comunicação eficaz representa no processamento paralelo.

O tempo gasto em comunicação depende, em primeiro lugar, de um bom projeto da aplicação paralela, com um dimensionamento adequado das sub-tarefas a serem designadas a cada processador segundo a arquitetura da máquina. Com isso determinado, o fator que vem a influenciar o tempo de comunicação é a velocidade com que os elementos processadores trocam informações. Se as informações são trocadas através de uma rede de comunicação, como é mostrado na seção seguinte, a velocidade da rede é determinante no tempo de comunicação. A velocidade de uma rede de comunicação pode ser medida através da "latência" (latency) e da "taxa de transferência" (bandwidth) que ela apresenta.

Uma vez iniciada a transmissão de dados, por latência entende-se o tempo que o primeiro elemento dos dados demora para chegar ao destino. A taxa de transferência é a quantidade de dados enviada por unidade de tempo, medida em bytes por segundo neste trabalho. Na seção 2.7 é feita uma discussão mais detalhada desses dois conceitos.

\subsection{Arquiteturas paralelas}

\subsubsection{Visão geral}

Muitas abordagens têm sido seguidas na pesquisa de arquiteturas que possam explorar o conceito de processamento paralelo. Essas abordagens podem ser divididas em duas classes principais: as que utilizam processadores que seguem a arquitetura seqüencial de von Neumann e as que utilizam arquiteturas não convencionais de elementos processadores, como os arranjos sistólicos. Embora as arquiteturas não convencionais tenham sido objeto de pesquisas importantes no campo de arquiteturas 
paralelas, na prática são os processadores do tipo von Neumann que têm sido efetivamente utilizados para processamento paralelo.

As máquinas mais usadas atualmente para processamento paralelo são da categoria MIMD (Multiple Instruction, Multiple Data). Duas variantes são possíveis: com memória compartilhada ou com memória distribuída. As duas variantes são importantes e utilizam diferentes paradigmas de programação para comunicação entre processadores, embora qualquer um desses paradigmas possa ser mapeado no outro, acrescentando-se uma camada de software de comunicação adicional. O primeiro desses paradigmas é o de memória compartilhada, mais fácil de programar. $O$ segundo é o paradigma de passagem de mensagens.

Máquinas com memória compartilhada apresentam uma limitação (bottleneck de von Neumann) quanto ao número de processadores. Máquinas com memória distribuída não apresentam essa limitação e o número de processadores pode atingir várias centenas. Uma tendência atual em máquinas comerciais é a utilização de arquiteturas híbridas, onde vários nós de processamento com vários processadores cada são utilizados. Cada processador compartilha uma memória única com os outros processadores do nó. Nós de processamento diferentes são interligados por uma rede de comunicação de alta velocidade.

Uma outra tendência são as máquinas que possuem memória distribuída mas com espaço de endereçamento comum, ou seja, cada processador pode uniformemente endereçar a memória de todos os outros processadores como se fosse uma grande memória compartilhada [HWA93].

A seguir são apresentados os tipos de arquiteturas de computadores para processamento paralelo e suas classificações, assim como uma visão mais aprofundada dos computadores MIMD, que formam uma classe na qual o objeto de estudo desse trabalho de mestrado está incluído. 


\subsubsection{Classificação de arquiteturas}

Uma das classificações mais usadas para arquiteturas de computadores é a classificação de Flyn. Segundo Flyn, as máquinas são enquadradas nas categorias SISD (Single Instruction Single Data), SIMD (Single Instruction Multiple Data), MISD (Multiple Instruction Single Data) e MIMD (Multiple Instruction Multiple Data):

- SISD: Uma única seqüência de instruções tratando de um único fluxo de dados.

Nessa categoria são colocados os computadores sequienciais comuns, que seguem o modelo arquitetural de von Neumann. Como exemplo pode-se citar os computadores pessoais da linha IBM PC. As máquinas mais recentes dessa linha possuem processadores que realizam operações paralelas internamente, embora continuem sendo classificadas como SISD.

- SIMD: Uma única sequiência de instruções tratando de mais do que um fluxo de dados.

Aqui a máquina possui um único controle de execução de instruções e várias unidades para processamento de dados. Uma mesma instrução é aplicada em vários dados ao mesmo tempo. Nessa categoria pode ser citado um dos precursores das arquiteturas paralelas, o ILLIAC-IV, da Universidade de Illinois (EUA) [ALM94].

- MISD: Mais de uma sequiência de instruções tratando de um único fluxo de dados.

Pode-se dizer que os computadores MISD referem-se a unidades de processamento independentes que trabalham sobre o mesmo fluxo de dados. Alguns autores afirmam não existir representantes dessa classe de computadores [TAN92] [DUN90]. Outros colocam como membros dessa classe os computadores que utilizam pipelines [ALM94]. 
- MIMD: Mais de uma sequuência de instruções tratando de mais do que um fluxo de dados.

Os representantes dessa categoria possuem unidades de processamento independentes que operam sobre conjuntos de dados diferentes.

Os computadores para processamento paralelo mais importantes da atualidade enquadram-se nessa categoria de arquitetura. Várias formas de implementação desses computadores podem ser usadas e serão discutidas mais adiante. Como exemplos dessa classe pode-se citar os atuais MPPs (Massively Parallel Processors) da Cray, como o T3D e T3E [CRA98], e as redes locais de computadores que podem trabalhar como uma máquina paralela, conhecidas como NOWs (Networks of Workstations).

Apesar de largamente utilizada, a classificação de Flyn não cobre adequadamente algumas arquiteturas existentes. [DUN90] sugeriu uma nova classificação para arquiteturas, e sua versão para a classe MIMD propõe a divisão dessa classe entre memória compartilhada e memória distribuída. A seção seguinte apresenta em maiores detalhes as arquiteturas MIMD.

\subsubsection{Detalhando a arquitetura MIMD}

Computadores classificados como MIMD podem ser de dois tipos diferentes em relação à organização de sua memória: memória compartilhada (multiprocessador) ou memória distribuída (multicomputador).

Nos computadores de memória compartilhada, várias unidades de processamento (processadores) são ligadas a uma mesma memória comum através de uma rede de interconexão. A comunicação entre os processadores se dá através da memória. Muitos fabricantes fornecem máquinas que possuem essa configuração, com um número limitado de processadores, como a Silicon Graphics, a Sun e fabricantes de máquinas baseadas nos chips Pentium da Intel.

Nem sempre as máquinas MIMD com memória distribuída são utilizadas para processamento paralelo. Em muitos casos, programas inteiros são distribuídos entre os processadores, aumentando apenas a taxa de execução dos programas e não a velocidade de execução de cada um deles. Para se utilizar essa arquitetura com 
processamento paralelo são necessários programas especialmente desenvolvidos para esse fim. A Figura 2-1 mostra uma arquitetura MIMD com memória compartilhada.

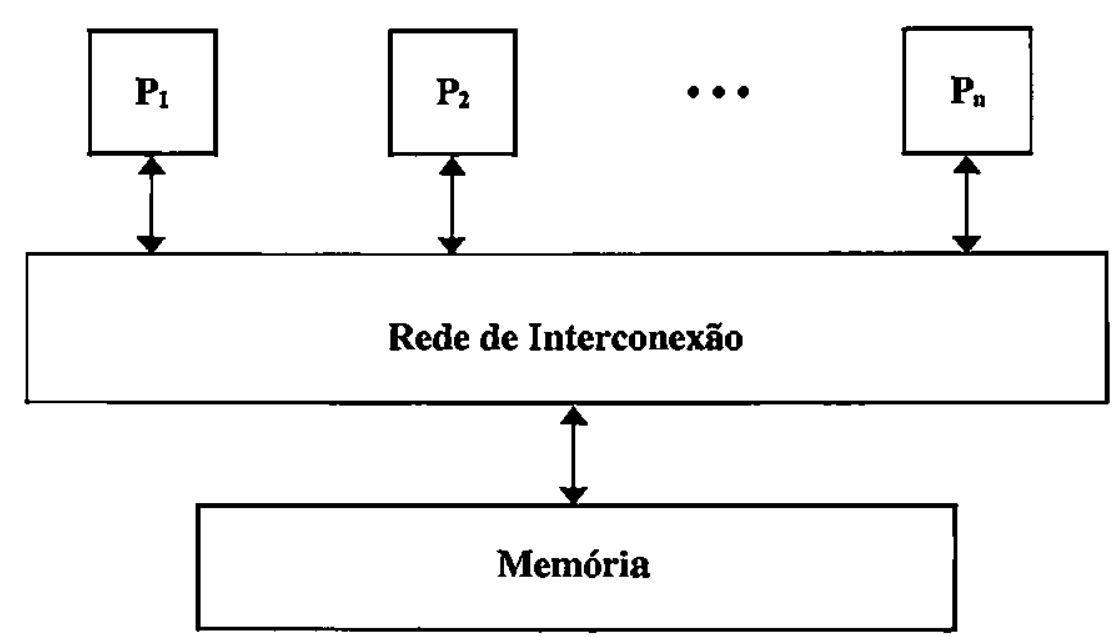

$\mathbf{P}_{i:}$ Processadores

\section{Figura 2-1 Arquitetura MIMD com memória compartilhada}

Nas máquinas MIMD com memória distribuída, uma coleção de processađores com memória própria (chamados de nós), é interligada através de uma ređe de comunicação. Essa đefinição simples pođe englobar desđe máquinas como o IBM SP2 até um sistema distribuído ou uma rede de computadores. A grande vantagem desse tipo de sistema é a sua facilidade de expansão. Pode-se utilizar um número muito grande de elementos processadores relativamente baratos, chegando-se a milhares de unidades, sem limitações importantes de hardware. A Figura 2-2 mostra uma representação dessa arquitetura. 


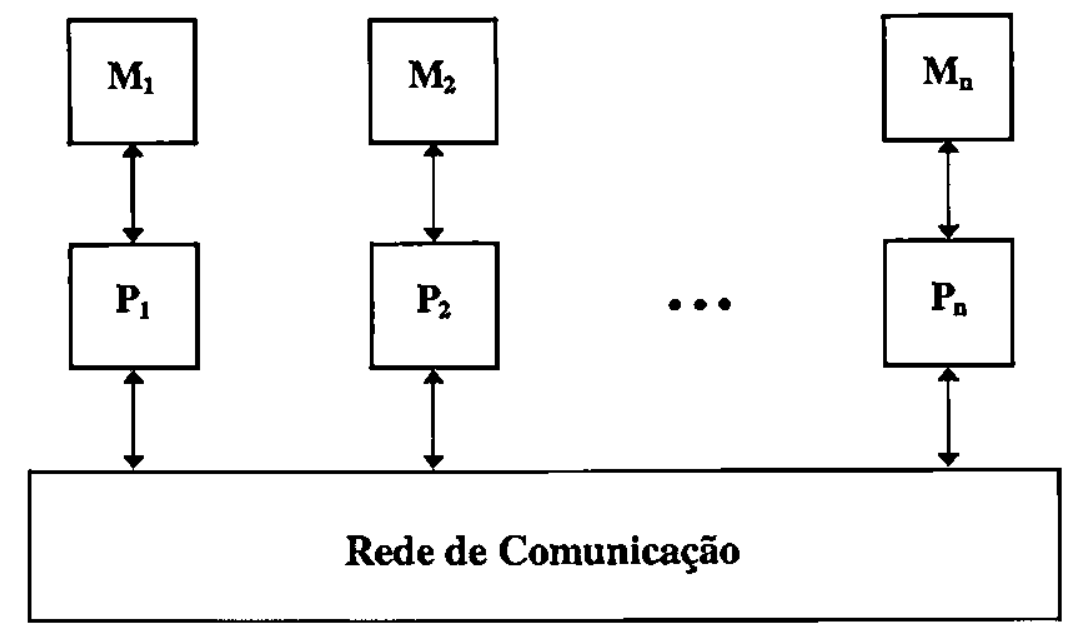

$\mathbf{M}_{i}:$ Memória do Processador $i$

$\mathbf{P}_{i}$ : Processadores

\section{Figura 2-2 Arquitetura MIMD com memória distribuída}

Para a troca de dados e sincronização de tarefas entre processadores, essas máquinas usam um paradigma de programação denominado Message Passing (passagem de mensagens). As mensagens são enviadas entre processadores através de pacotes que viajam na rede que conecta os nós. A eficiência dessa rede, assim como a velocidade do processador, são fundamentais para se obter um bom desempenho nessas arquiteturas. Em máquinas paralelas comerciais, como o IBM SP2, as redes geralmente são proprietárias e incorporam hardware e protocolos próprios para atingir o máximo desempenho.

\section{Topologias de redes de interconexão}

A topologia, ou seja, a forma como são conectados os elementos processadores na formação das redes, é um ponto de estudo de grande importância nas máquinas paralelas. A topologia pode tornar uma máquina mais ou menos adequada para a solução de uma determinada classe de problemas. Dois fatores contribuem para isso: o desempenho da rede pode não ser uniforme entre cada par de processadores e certos problemas podem aproveitar melhor que outros essa característica. 
As redes de conexão entre os nós podem ser estáticas ou apresentar comportamento dinâmico. Serão apresentados a seguir os tipos de redes mais comuns encontrados em máquinas paralelas MIMD e exemplos de computadores que se enquadram em algumas categorias.

\section{a) Redes estáticas (Figura 2-3):}

- Malhas e anéis:

A malha de uma dimensão é o tipo mais comum de topologia, também conhecida como array linear. Nesse caso, cada nó é conectado ao seu vizinho em linha reta, sendo que os nós interiores têm duas conexões e os nós das pontas só apresentam ưma conexão. Se os nós das pontas são ligados um ao outro, cria-se uma topologia anel. Aumentado-se a malha para $\mathrm{k}$ dimensões, o grau dos nós do interior fica sendo $2 \mathrm{k}$. Malhas de dimensão 2 são as mais comuns, estando nessa categoria o ILLJAC IV. Outro representante da classe das malhas é o Intel Paragon [LIU95].

\section{- Estrela:}

Na topologia estrela um elemento central liga-se a todos os outros nós. Toda a comunicação passa pelo elemento central, tornando-se impraticáveis configurações com muitos nós.

- Árvore binária:

Cada nó interior da árvore tem 3 conexões: com o pai e mais dois filhos. As folhas possuem apenas ligação com o pai, e a raiz só se liga com seus dois filhos. Um dos problemas com essa estrutura é que o tráfego de comunicação se torna mais pesado quanto mais próximo se estiver da raiz. Uma forma de amenizar esse problema é o uso da chamada árvore fat (gorda). Nessa árvore, o número de canais de comunicação do filho com o pai aumenta quanto mais próximos estiverem os nós da raiz. A Thinking Machines Corporation usa essa topologia na sua máquina CM-5 [LU94]. 
- Completamente conectada:

Cada nó se liga a todos os outros nós através de canais individuais de comunicação. Uma implementação com muitos nós tornaria impraticável a construção dessa rede, além do custo da rede ser muito alto em relação ao preço final da máquina.

- Hipercubo:

Num hipercubo, o número de nós é dado por $\mathrm{N}=2^{\mathfrak{n}}$, onde $\mathrm{n}$ é a dimensão. Em uma dimensão 3, um hipercubo é um cubo com um nó em cada um dos oito vértices. O grau do nó é sempre n. Várias máquinas, como o CM-2, o Intel iPSC/2 e o nCUBE seguem a topologia de hipercubos. Por apresentar uma escalabilidade pobre e pela dificuldade de construção de hipercubos com muitos nós, essa topologia tem sido substituída em máquinas mais recentes.

- CCC (Cube-Connected Cycles)

O CCC é uma adaptação dos hipercubos. Para se construir um CCC, pega-se um hipercubo de dimensão k e substitui-se cada vértice do hipercubo por um anel com $\mathrm{k}$ elementos. A grande vantagem do $\mathrm{CCC}$ é que cada elemento agora possui apenas 3 conexões cada em vez de $\mathrm{k}$ conexões como antes. 


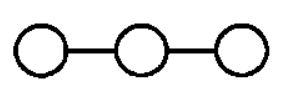

Array linear

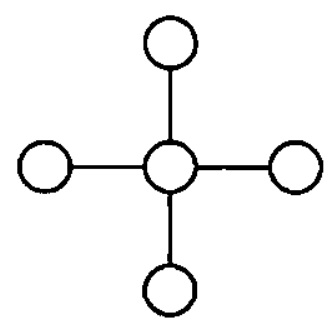

Estrela

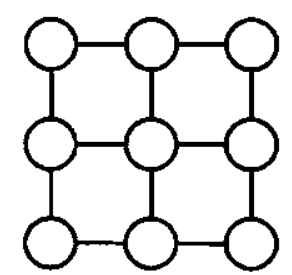

Malha

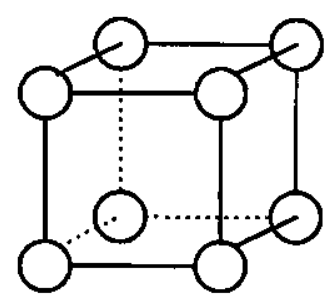

Hipercubo

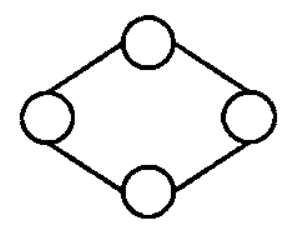

Anel

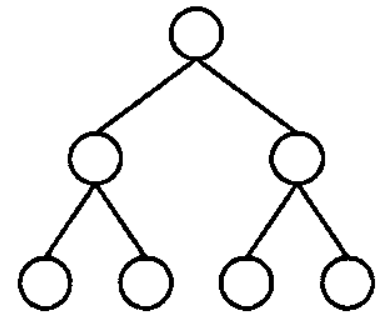

Árvore binária

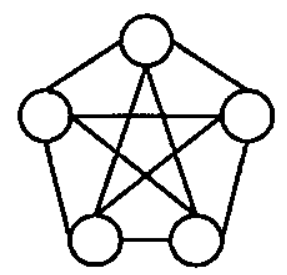

Completamente conectada

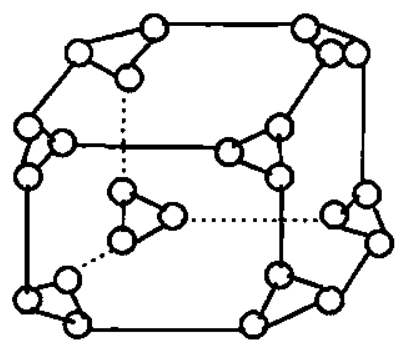

Cube-Connected Cycles

Figura 2-3 Topologias estáticas para redes de comunicação

b) Redes dinâmicas (Figura 2-4)

Para aplicações de propósito gerais, é mais adequada a implementação de redes de comunicação dinâmicas do que das redes estáticas apresentadas. Nas redes dinâmicas, a comunicação ponto-a-ponto entre os processos paralelos é alcançada 
diretamente sem que a mensagem tenha que passar por outros processadores intermediários.

Entre os tipos de redes dinâmicas pode-se citar os barramentos (bus), as redes de interconexão multi-estágio (mutistage interconections networks) e as chaves crossbar:

- Barramentos:

Nos barramentos, os elementos processadores e periféricos ficam conectados em um barramento comum de comunicação. Apenas uma transmissão por vez pode ocorrer, sendo que sempre que um elemento quer transmitir ele deve disputar esse meio comum (o barramento) com os outros elementos que também estão desejando transmitir mensagens. Para controlar essa disputa existem padrões que especificam a forma como será realizada a arbitragem do barramento. Por ter essa característica de muitos elementos compartilhando o tempo de uso do barramento (time-sharing bus), a inclusão de muitos elementos diminui o desempenho de comunicação.

-Crossbar:

Nas redes Crossbar os elementos possuem duas portas para conexão com a chave. A ligação ou não dessa chave determina a conexão (veja Figura 2-4). Nesse esquema, vários elementos podem comunicar-se ao mesmo tempo, aumentando a taxa de transferência geral do sistema. A latência de transmissão também é favorável, uma vez que os dados fluem diretamente entre os elementos através da chave lógica. As redes crossbar estão entre as melhores formas de conexão entre elementos processadores ou entre processadores e memória em máquinas de memória compartilhada. A desvantagem que elas apresentam é o alto custo de implementação quando o número de elementos $(\mathrm{N})$ é muito grande, já que o número de chaves lógicas cresce segundo $\mathrm{N}^{2}$.

- Redes multi-estágio:

Nessas redes, os elementos de processamento são ligados a várias chaves do tipo crossbar de pequena dimensão (geralmente $2 \times 2$ ), que por sua vez se interligam a outra camada ou estágio de crossbars, e assim sucessivamente até que a última 
camada se liga novamente aos elementos. As conexões entre os estágios são estáticas, ou seja, a saída 1 da primeira chave, por exemplo, s6 se liga com a entrada 0 da quinta chave do segundo estágio. Com chaves $2 \times 2$, necessita-se de $\log _{2} \mathrm{~N}$ estágios com $\mathrm{N} / 2$ chaves em cada estágio para se conectar $\mathrm{N}$ elementos. $\mathrm{O}$ custo de uma rede cai de $\mathrm{N}^{2}$ para $\mathrm{N} / 2 * \log _{2} \mathrm{~N}$ passando-se de uma rede crossbar para uma rede multi-estágio.

As redes multi-estágio são o meio termo entre as redes em barramento e as redes crossbar. Elas apresentam conectividade total entre os elementos, taxa de transferência maior que os barramentos e menor custo que as redes crossbar, embora com uma latência maior.

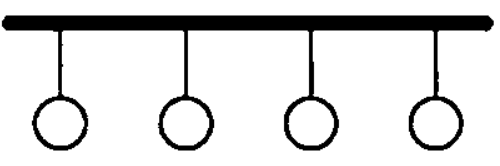

Barramento

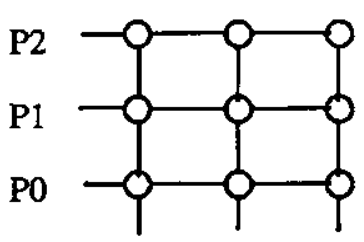

P0 P1 P2

\section{Crossbar}

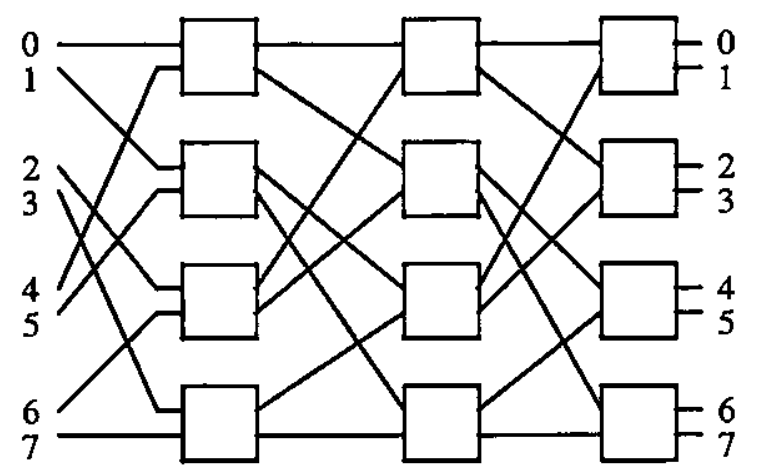

Multi-estagio

Figura 2-4 Topologias dinâmicas para redes de comunicação 


\section{LANs e processamento paralelo}

Recentemente, tem crescido o uso de redes locais de computadores (LANs) na síntese de máquinas paralelas virtuais. $O$ uso de redes de computadores como uma máquina paralela tem se tornado viável devido ao avanço na tecnologia e velocidade das redes locais disponíveis no mercado. Redes como ATM, Myrinet e FDDI, por exemplo, atingem taxas de comunicação na ordem de centenas de Mbits por segundo. Essas redes permitem a construção de máquinas paralelas com o uso de estações de trabalho ou computadores pessoais, exibindo bom desempenho de comunicação em comparação com máquinas comerciais muito mais caras.

O poder de processamento dessas máquinas é equiparável ao dos MPPs atuais. Mesmo processadores de computadores pessoais mais comuns, como, por exemplo, o Intel Pentium $\Pi$ e o AMD K6, apresentam um desempenho que tem se aproximando do desempenho dos processadores mais velozes do mercado, como por exemplo, o DEC Alpha que equipa o Cray T3E.

Os MPPs podem ter centenas ou milhares de processadores e apresentam os maiores desempenhos disponíveis em sistemas voltados para processamento paralelo. O custo, entretanto é elevado podendo atingir vários milhões de dólares para um sistema com configuração típica.

Aplicações que tenham relativamente poucos processos paralelos se comunicando podem atingir o mesmo desempenho dos MPPs em redes de computadores. Com a evolução do hardware das redes locais de comunicação e protocolos apropriados a diferença na velocidade de execução dos programas paralelos nas redes de computadores em relação aos MPPs tem se tornado menor ou mesmo deixado de existir.

\subsubsection{O SPP2}

A máquina paralela SPP2 [TRI95b], desenvolvida no Laboratóri 
Computação de Alto Desempenho LCAD-USP, é uma arquitetura baseada no hardware de microcomputadores pessoais. Os nós de processamento são compostos por placas de computadores pessoais (até 4 processadores) com memória compartilhada. Os nós são ligados por uma rede de comunicação Myricom Myrinet de alta velocidade (até 2,56 Gbps) para a troca de mensagens. O SPP2 é uma arquitetura escalável, podendo conter até 256 nós.

Os nós são ligados a um host através de uma rede Ethernet ou Fast Ethernet. $\mathrm{O}$ host funciona como servidor de arquivos e também provê boot remoto do sistema operacional Linux aos nós. A Figura 2-1 mostra, de forma simplificada, a organização do SPP2.

Atualmente a máquina protótipo dispõe de 8 nós com processador Pentium de $133 \mathrm{MHz}$ e 16 Mbytes de memória por nó, interligados por uma rede Ethernet. Uma nova versão da máquina, o SPP3, conta com uma quantidade maior de memória por nó, além da instalação de uma rede Myrinet e a evolução para chips Pentium II da Intel. Está prevista também a instalação de discos rígidos locais para cada nó, tornando mais rápido o armazenamento e acesso de dados individuais dos processos, ou seja, dados que serão utilizados apenas para a computação específica em cada nó, não sendo necessariamente compartilhados com outros processos paralelos.

Uma grande variedade de ferramentas para o desenvolvimento de aplicações paralelas compatíveis com a arquitetura do SPP2 e o sistema operacional Linux pode ser encontrada na Internet. Algumas das ferramentas que podem ser utilizadas no SPP2 padrão (com protocolo TCP/IP) são os ambientes de passagem de mensagens MPI e PVM, o ambiente de auxílio à paralelização de código Fortran $P 2 d$ e os de análise de desempenho XPVM e XMPI. Outra ferramenta está sendo desenvolvida no LCAD, como um trabalho de mestrado, para monitorar e gerenciar o SPP2 através de navegadores WWW pela Internet.

O apêndice B descreve a máquina SPP3 desenvolvida no LCAD - USP. 


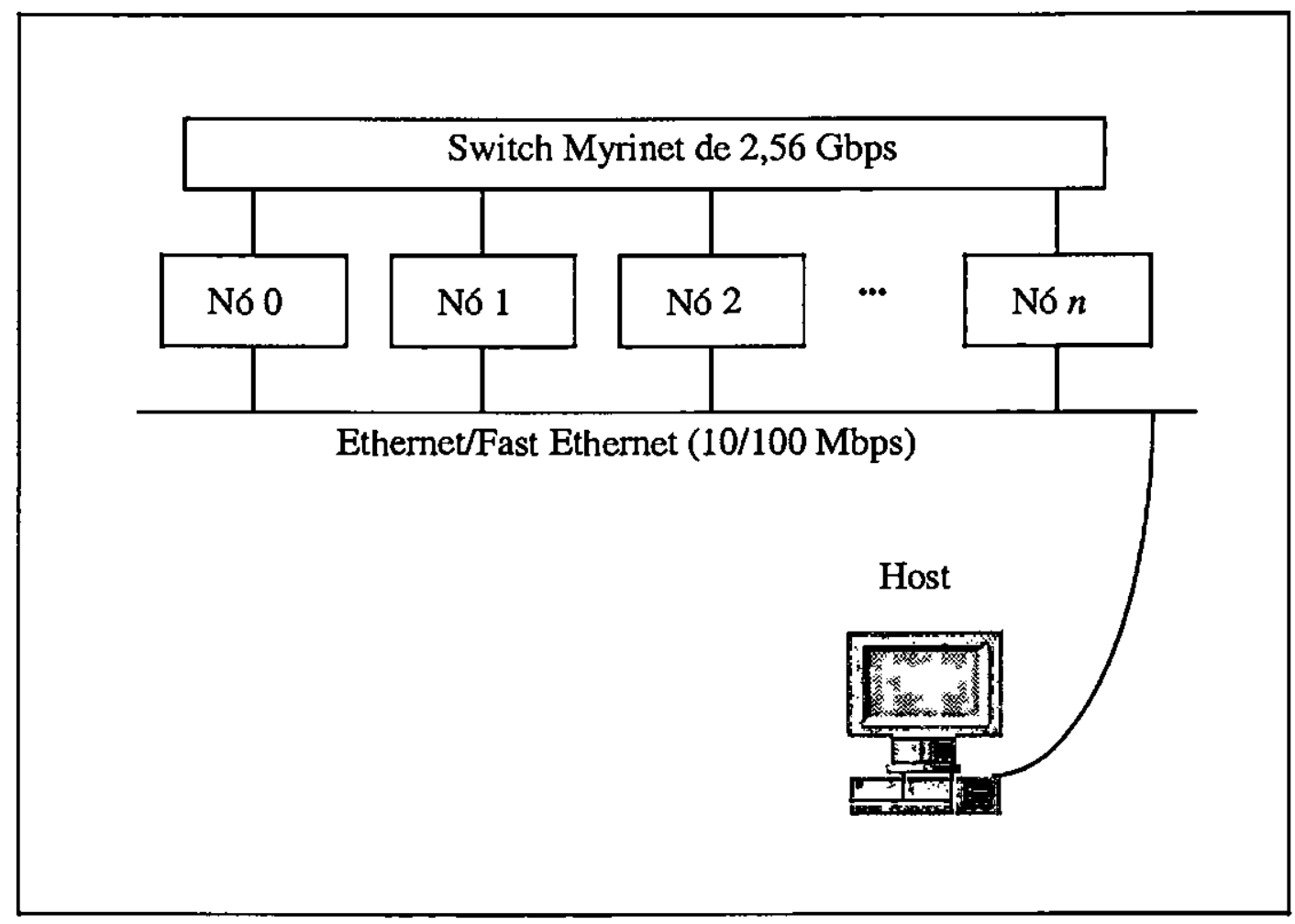

Figura 2-1 Organização do SPP2

O SPP2 $\varepsilon$ uma arquitetura híbrida entre MIMD com memória compartilhada e MIMD com memória distribuída. Os processadores de um mesmo nó comunicam-se entre si através da memória compartilhada. Quando processadores de nós diferentes se comunicam eles utilizam a rede de comunicação. Aplicações paralelas desenvolvidas para uma arquitetura desse tipo devem agrupar tarefas que possuem muita comunicação umas com as outras em um mesmo no, uma vez que a comunicação em memória é mais rápida do que a comunicação através da rede.

O controle da distribuição de processos para os processadores de um mesmo nó pode ser feito pelo sistema operacional, enquanto a distribuição entre nós fica a cargo de sistemas de nível mais alto como as bibliotecas para processamento paralelo MPI e PVM discutidas mais adiante. Neste trabalho de mestrado será estudada a melhor forma de distribuir e endereçar processos nessa arquitetura utilizando os recursos disponíveis no PVM padrão e os recursos disponíveis na API (Application Program Interface, ou interface de programação) Fast-Messages. 


\subsection{Programação paralela}

No processamento paralelo uma tarefa é dividida em sub-tarefas que vão ser executadas ao mesmo tempo e que cooperam entre si na realização da tarefa original. Para isso, o programador de uma aplicação paralela deve dispor de meios para [ALM94]:

1. Definir um conjunto de sub-tarefas a serem executadas em paralelo.

2. Iniciar e terminar a execução das sub-tarefas.

3. Coordenar e especificar a interação das sub-tarefas quando elas estão executando.

Dependendo do nível do paralelismo e da arquitetura da máquina, esses itens podem ser realizados tanto pelo programador através de um suporte na linguagem de programação utilizada ou serem feitos automaticamente por um compilador.

As atividades relacionadas com o item número 1 incluem a definição do que é paralelizável em um algoritmo, sua divisão em sub-tarefas e a distribuição das subtarefas nos elementos de processamento disponíveis. Uma discussão sobre esse assunto já foi abordada na seção 2.2, ponderando sobre a influência da granulosidade e da arquitetura da máquina no desempenho de aplicações paralelas.

Os itens 2 e 3 são de maior importância no momento e serão melhor definidos nas seções seguintes.

\subsubsection{Iniciando e terminando a execução de sub-tarefas}

Entre os mecanismos mais comuns utilizados para o controle da ativação de processos paralelos, pode-se citar o forkjjoin, o parbegin/parend, o doall e chamdas a subprogramas.

\section{Fork/Join}


A idéia por trás de fork/join é criar um novo processo filho idêntico ao pai quando um comando "fork p" é encontrado no código, fazendo com que o controle de execução do processo filho inicie no ponto p. O comando "join $x, q$ " serve para controlar o sincronismo entre os processos iniciados. A variável x é subtraída de 1 e se o seu valor for igual zero, salta o controle para o ponto q do código. Se não for zero, a execução daquela tarefa é terminada. A Figura 2-1 exemplifica a operação de um trecho de código que utiliza fork/join.

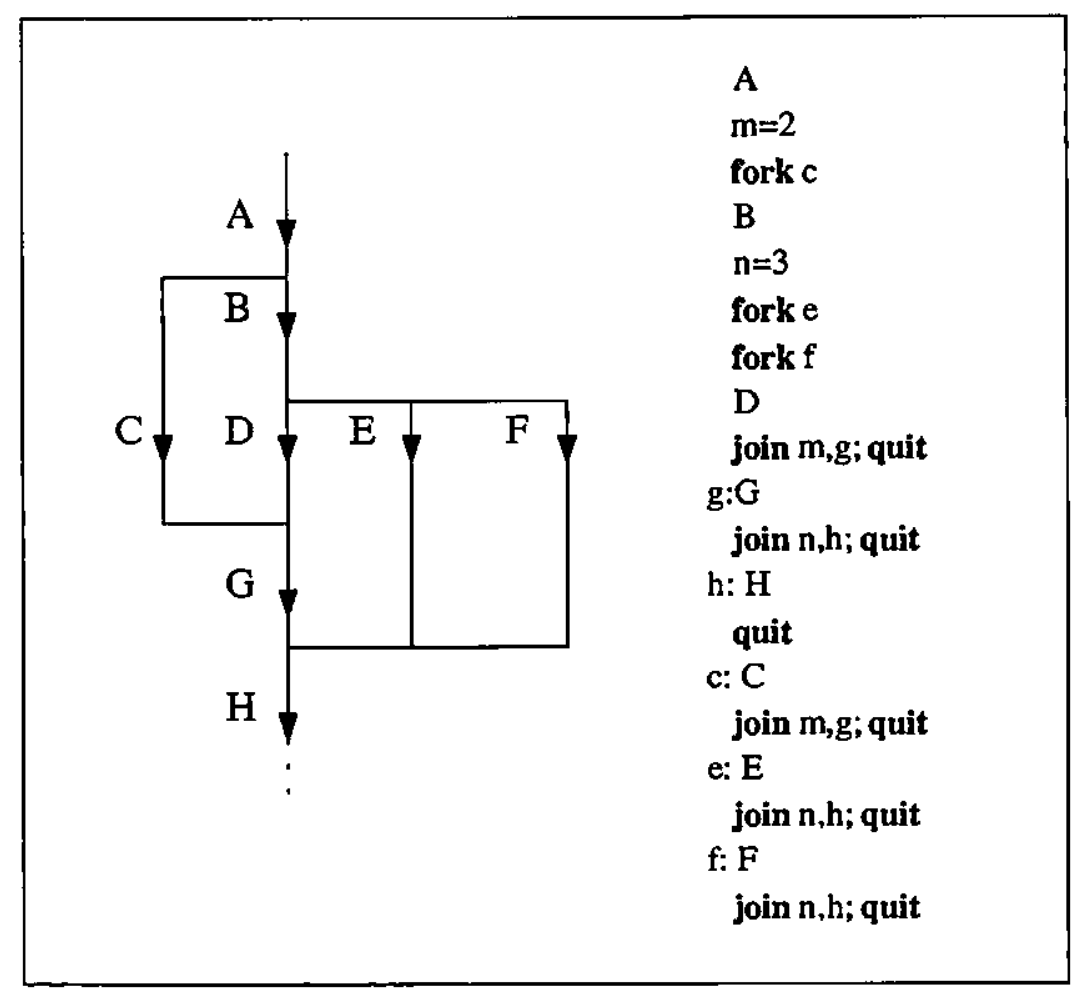

Figura 2-1 Exemplo do mecanismo fork/join

Fork/join é um recurso poderoso e versátil para o controle de execução de tarefas paralelas. Mas sua utilização merece cautela, pois a característica nãoestruturada e o controle de join totalmente a cargo do programador podem levar a erros de programação e à construção de códigos difíceis de se entender.

\section{Parbegin/Parend}


Parbegin/parend é um mecanismo parecido com fork/join, mas apresenta menos versatilidade. Os processos filhos iniciados após um parbegin devem todos terminar no mesmo parend. A vantagem é uma maior facilidade na programação em relação ao fork/join. Na Figura 2-2, os comandos entre parbegin e parend são executados em paralelo, enquanto os comandos entre begin e end são seqüenciais.

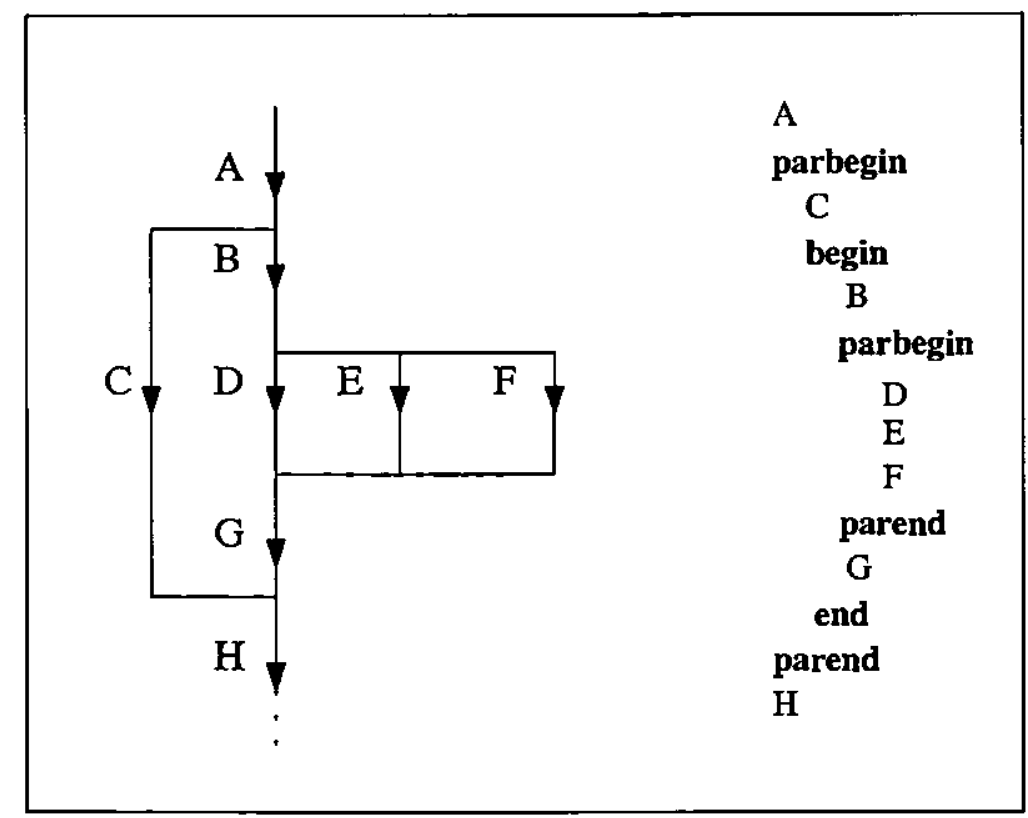

Figura 2-2 Exemplo do mecanismo Parbegin/Parend

\section{Doall}

O comando doall é utilizado em trechos de código que apresentam iterações (loops) e atua como se fosse um parbegin que coloca as várias iterações em paralelo. Uma diferença importante entre parbegin e doall é que no primeiro sabe-se em tempo de codificação quantos serão os processos paralelos iniciados, enquanto no segundo o número de processos é dinâmico, uma vez que os loops podem variar de tamanho em tempo de execução da aplicação.

A utilização de doall requer uma análise da possibilidade de sua implementação, já que em alguns loops os dados de uma iteração são dependentes da 
iteração anterior, criando uma seqüência de eventos que não podem ocorrer em paralelo.

\section{Subprogramas}

Uma outra forma de ativar processos paralelos é através da chamada de subprogramas ou procedimentos que executam em paralelo com o programa que os chamou. Utiliza-se o subprograma paralelo como se ele fosse um subprograma convencional. Algumas linguagens de programação comerciais, como PL/1 e Ada, oferecem esse mecanismo.

\subsubsection{Coordenando a execução paralela}

Os processos paralelos, para poderem cooperar entre si, necessitam trocar dados e informações de sincronização utilizando alguma forma de comunicação. No modelo de memória compartilhada, isso é feito através do uso de variáveis de acesso comum aos processos. Em memória distribuída (ou modelo de Passagem de Mensagens), os processos estabelecem canais logicos de comunicação através da rede de interconexão, mandando pacotes de informação (mensagens) por esses canais.

Um exemplo dos dois modelos é mostrado na Figura 2-1. A Figura 2-1 (a) representa os modelo de variáveis compartilhadas e a Figura 2-1 (b) representa o modelo de passagem de mensagens.

\section{Sincronização em memória compartilhada}

A sincronização em memória compartilhada ocorre basicamente com a atribuição de valores a variáveis que todos os processos enxergam. $\mathrm{O}$ acesso a 


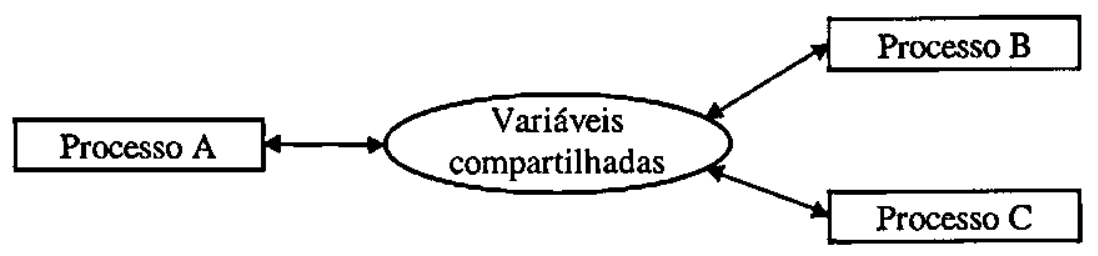

(a)

Processo D

Troca de mensagens

(Canal de comunicaçāo)

Processo E

(b)

Figura 2-1 Mecanismos para comunicação entre processos

variáveis compartilhadas para a sincronização e troca de dados deve ser controlado para evitar anomalias que possam surgir da disputa para o acesso dessas variáveis (race conditions). Se, por exemplo, um processo lề uma variável antes que um segundo processo escreva um novo valor nessa variável, pode ocorrer uma falha de sincronismo dependendo de qual valor deveria ser lido pelo segundo processo.

Os mecanismos de sincronização devem dispor de formas para se alterar variáveis em operações atômicas, ou seja, uma vez iniciadas, outros processos não têm acesso às variáveis antes do término da operação. Entre os mecanismos para controlar o acesso a variáveis e para sincronizar processos paralelos estão test-and-set, semáforos, monitores, barreiras e fetch-and-add [ALM94] [HWA93].

\section{Sincronização e comunicação com Passagem de Mensagens}

$\mathrm{Na}$ passagem de mensagens, o programador deve dispor de funçð̃es para realizar o envio de mensagens de um processo para outro, da forma "ENVIA mensagem PARA destino" e funções para o recebimento de mensagens do tipo "RECEBE mensagem DE fonte". Dois modelos de programação são possíveis para a 
troca de mensagens: a que usa comunicação "síncrona" e a que usa comunicação "assíncrona".

$\mathrm{Na}$ comunicação síncrona o processo que envia só continua sua execução quando o processo que recebe confirmar a transação. O ENVIA é dito ser "bloqueante" quando ele bloqueia a execução daquele processo enquanto a transmissão não tiver sido completada. O Rendez-vouz e o RPC (Remote Procedure Call) [ALM94] são exemplos de mecanismos síncronos e bloqueantes.

No caso assíncrono, o processo que manda a mensagem continua sua execução após o ENVIA, sem esperar que o processo destino confirme a transação. PVM e Linda exemplificam o mecanismo de comunicação assíncrono.

\subsection{Bibliotecas de Passagem de Mensagens}

Conforme discutido no item anterior, passagem de mensagens (Message Passing) é um paradigma de programação usado amplamente em computadores paralelos, especialmente nos chamados Computadores Paralelos Escaláveis (Scalable Parallel Computers, ou SPCs) e nas Redes de Computadores. Mesmo havendo muitas variações, o conceito básico de processos se comunicando através de mensagens é bem compreendido. Nos últimos anos, muitos sistemas têm demonstrado que a passagem de mensagens pode ser eficiente e implementada com um padrão em diferentes plataformas de software e hardware. Serão descritos nos itens seguintes os dois sistemas de passagem de mensagens mais utilizadas atualmente: PVM e MPI.

\subsubsection{PVM}

O sistema PVM (Parallel Virtual Machine) é composto por uma biblioteca de programação e programas auxiliares, permitindo que computadores conectados por redes de comunicação formem uma "máquina paralela virtual" distribuída onde podem ser executadas aplicações de processamento paralelo. Esses computadores podem ter arquiteturas diferentes, como estações de trabalho monoprocessador de 
vários fabricantes ou multiprocessadores com memória compartilhada. O PVM é baseado nos seguintes princípios:

- Conjunto de processadores configurável pelo usuário: o usuário determina o conjunto de máquinas nas quais seu programa será executado. Essas máquinas podem ter memória compartilhada ou distribuída;

- Visão do hardware: aplicações podem ver o hardware como uma coleção de unidades de processamento virtuais iguais ou podem explorar as capacidades específicas de certas máquinas, atribuindo tarefas especiais ao computador mais apropriado;

- Computação baseada em processo: a unidade de paralelismo é a sub-tarefa, um processo sequiencial que alterna entre comunicação e processamento;

- Modelo de passagem de mensagens: as sub-tarefas paralelas cooperam entre si através do envio e recebimento de mensagens;

- Suporte a heterogeneidade: máquinas diferentes que podem estar em redes diferentes podem fazer parte da "máquina virtual";

- Suporte a multiprocessadores: os métodos para troca de mensagens nativos da máquina são utilizados para tirar proveito da maior velocidade que oferecem.

O sistema PVM é composto por duas partes. A primeira é um software daemon (pvmd) que é executado nas máquinas que fazem parte da máquina virtual. Ao ser executado é criada a máquina virtual com os computadores listados em um arquivo texto. A segunda parte é uma biblioteca de rotinas necessárias para a cooperação entre as tarefas de uma aplicação. Essa biblioteca provê rotinas para troca de mensagens, coordenação de tarefas e modificação da máquina virtual, entre outras.

Os processos paralelos se comunicam através dos daemons. Quando um processo quer transmitir uma mensagem, ela é mandada para o pvmd da máquina na qual o processo está sendo executado, que então se comunica com o pvmd da máquina destino, e este entrega a mensagem ao processo correto. Como o PVM é destinado a executar aplicações paralelas em um conjunto heterogêneo de arquiteturas, as mensagens podem ser convertidas para um formato padrão de dados (XDR) antes da 
transmissão e então convertidas para a arquitetura da máquina destino depois da transmissão.

Com a utilização de diferentes arquiteturas, os programas que utilizam a biblioteca PVM devem ser compilados para cada máquina de arquitetura diferente que faz parte da máquina virtual. Cada máquina deve ter sua versão do código objeto da aplicação armazenada para poder executá-lo quando requerido.

A máquina virtual permite o controle de processos, que é a habilidade de iniciar e terminar tarefas e identificar quais tarefas estão sendo executadas e onde. Além disso ela permite o gerenciamento de recursos (hosts) disponíveis dinamicamente, possibilitando a entrada e saída de máquinas na máquina virtual. A tolerância a falhas também é suportada, permitindo o desenvolvimento de aplicações que tenham um tempo longo de execução. Numa eventual falha de um dos elementos processadores a aplicação pode se recuperar e assim não perder todo o trabalho já realizado. Uma descrição da arquitetura de comunicação no PVM padrão sobre protocolo TCP/IP é apresentada no apêndice A

\subsubsection{MPI}

O MPI (Message Passing Interface) é um padrão para bibliotecas de passagem de mensagens definido por um Fórum composto por mais de 80 pessoas do meio acadêmico e da indústria. O Fórum MPI (MPIF) vem trabalhando atualmente na versão 2 do padrão, mas as implementações hoje encontradas tanto em domínio público como as implementações proprietárias criadas por fabricantes de máquinas seguem a versão 1 [SNI96].

A motivação para a criação de um padrão ocorreu porque cada fabricante de MPPs (Massively Parallel Processors) estava criando uma API proprietária para passagens de mensagens. Dessa forma, as aplicações paralelas desenvolvidas para uma plataforma não podiam ser utilizadas em outra plataforma. Criando-se um padrão, e cada fabricante desenvolvendo a implementação de MPI mais propícia para 
sua plataforma, tornou-se possível a construção de programas utilizando essa biblioteca que são facilmente compilados em várias máquinas diferentes.

Apesar da versão MPI-1 especificar que é possível a troca de mensagens entre máquinas de arquiteturas diferentes, ela não proíbe implementações direcionadas para um conjunto de máquinas homogêneas, e não exige que essa implementação deva manter interoperabilidade com máquinas diferentes [SNI96]. Na prática as implementações do MPI-1 não interoperam entre si [GEI96]. Isso significa que, se quisermos usar o SPP2 em conjunto com uma workstation para a execução de um programa paralelo, não poderemos utilizar o MPI como sistema de passagem de mensagens.

Uma desvantagem do MPI é que não está disponível na versão 1 a criação dinâmica de processos, mas este é um dos pontos principais do MPI-2. Também não estão disponíveis no MPI-1 e não se cogita na versão 2 o conceito de máquina virtual, a tolerância a falhas, e o gerenciamento de recursos.

Apesar de ser uma biblioteca complexa que conta com 129 funções, com apenas 6 delas é possível solucionar um grande número de problemas. Essa funções são as seguintes:

- MPI_INIT

- MPI_FINALIZE

- MPI_COMM_SIZE

- MPI_COMM_RANK

- MPI_SEND

- MPI_RECV
Inicia uma computação com MPI;

Termina uma computação;

Determina o número de processos;

Determina o ID do processo;

Envia uma mensagem;

Recebe uma mensagem.

\subsection{Redes locais de comunicação}


Uma vantagem do uso de redes de computadores para processamento paralelo é a flexibilidade na construção das arquiteturas. Utilizando-se chaves para o roteamento de pacotes por exemplo, pode-se construir topologias com muitas máquinas que vão atender as necessidades de uma classe grande de aplicações. A escalabilidade das arquiteturas, ou seja, sua capacidade de crescimento, é grande no caso do uso de chaves na rede de comunicação, com pouca perda de desempenho em comparação com redes baseadas em barramentos seriais. $O$ hardware das redes locais de alto desempenho têm seguido essa tendência.

Interfaces de rede modernas são cada vez menos dependentes do processador da máquina a qual estão conectadas. A vantagem dessas novas interfaces é que elas permitem uma maior concorrência na execução dos serviços de comunicação, uma vez que elas podem iniciar o processamento desses serviços enquanto o processador está ocupado.

É importante que o software de comunicação evolua assumindo a idéia de que o hardware é capaz de alta taxa de transferência (na ordem de Gigabits por segundo), é baseado em chaves para roteamento de pacotes (podendo não dispor de artifícios como broadcast) e contém lógica interna capaz de livrar a CPU do processamento de certas partes do protocolo de comunicação.

O software de rede existente hoje em dia muitas vezes não acompanha a evolução do hardware. Geralmente se assume que o hardware de comunicação é muito mais lento que as CPUs, permitindo-se por exemplo várias cópias de dados entre buffers desde que o momento que o dado chega à interface até o momento em que ele é finalmente entregue ao buffer da aplicação do usuário. Isso adiciona um overhead muito grande que não pode ser tolerado numa rede de alto desempenho.

Para diminuir esse overhead, o software deve diminuir o papel do sistema operacional na comunicação. Não se pode, para cada pacote a ser transmitido, mudar o controle para o modo super-usuário, carregar e transferir o controle para o driver apropriado, processar os dados da mensagem, recarregar a aplicação do usuário e passar a ela novamente o controle. Ao sistema operacional deve-se deixar o papel de iniciar o processo de transferência de dados, sendo que todo o trabalho pode ocorrer em nível de usuário, tornando o processo mais rápido. 
Vê-se então que não basta o hardware de uma rede de comunicação ser rápido para se ter a velocidade que ele oferece disponível às aplicações do usuário. É necessário também que o software seja projetado de forma eficiente. Caso contrário, o desempenho geral da rede fica limitado pelo overhead elevado gerado pelos protocolos de comunicação e pelo sistema operacional.

A rede de comunicação Myricom Myrinet, estudada nesse projeto, tem as características apropriadas para alto desempenho.

\subsubsection{Myrinet}

A rede local Myrinet tem suas raizes no projeto do multicomputador experimental Caltech Mosaic, desenvolvido nos EUA para processamento paralelo de granulosidade baixa. Os pesquisadores que trabalharam na rede de comunicação desse computador fundaram a empresa Myricom, Inc [MYR98] e lançaram a linha de produtos para redes de alta velocidade denominada Myrinet.

A Myrinet padrão é composta por roteadores, placas de interface de rede e cabos para conexão. As placas de interface podem ser para os barramentos SBUS ou PCI, garantindo sua utilização em uma grande quantidade de máquinas diferentes. As placas ligam-se ao roteador por meio de uma interface paralela de oito bits. Os cabos podem ter tamanho desde 30 centímetros até alguns metros, dependendo do tipo de adaptador e roteador utilizados. São oferecidos roteadores e adaptadores do tipo $L A N$ (Local Area Network) e SAN (System Area Network). O tipo LAN é adequado para redes locais do tamanho de uma sala, enquanto que o tipo SAN cobre pequenas distâncias, sendo apropriado para a construção de máquinas tipo multicomputador em gabinetes.

A velocidade de um canal de comunicação na Myrinet chega a 1,28 Gbps, sendo que uma conexão contém 2 desses canais, possibilitando a comunicação fullduplex, ou seja, nos dois sentidos ao mesmo tempo a uma taxa de 2,56 Gbps.

Uma das formas para atingir alto desempenho na comunicação é a utilização de protocolos de roteamento do tipo cut-through que evitam o armazenamento do pacote nos roteadores. No roteamento tradicional, denominado store-and-forward (armazena-e-passa adiante), os pacotes são armazenados em cada roteador, tendo o 
checksum verificado e só então o pacote é passado adiante. No roteamento cutthrough apenas o header do pacote é decodificado e o pacote é enviado diretamente para o canal adequado, agilizando o processo de transferência.

Pode ocorrer que canal adequado esteja ocupado por outra comunicação, sendo necessário o armazenamento do pacote naquele roteador intermediário até que o canal esteja livre. A Myrinet conta com um controle de fluxo em cada roteador, impedindo que mais informação seja mandada enquanto não for possível passá-las adiante. Com isso, evita-se o uso de memória extra para se armazenar pacotes momentaneamente impossibilitados de prosseguirem.

As placas de interfaces de rede também cumprem seu papel na busca por uma maior velocidade de transmissão. As interfaces Myrinet são componentes ativos, contando com processador e memória próprios, e executam um programa dedicado à comunicação de dados. Um diagrama de blocos da placa é mostrado na Figura 2-1.

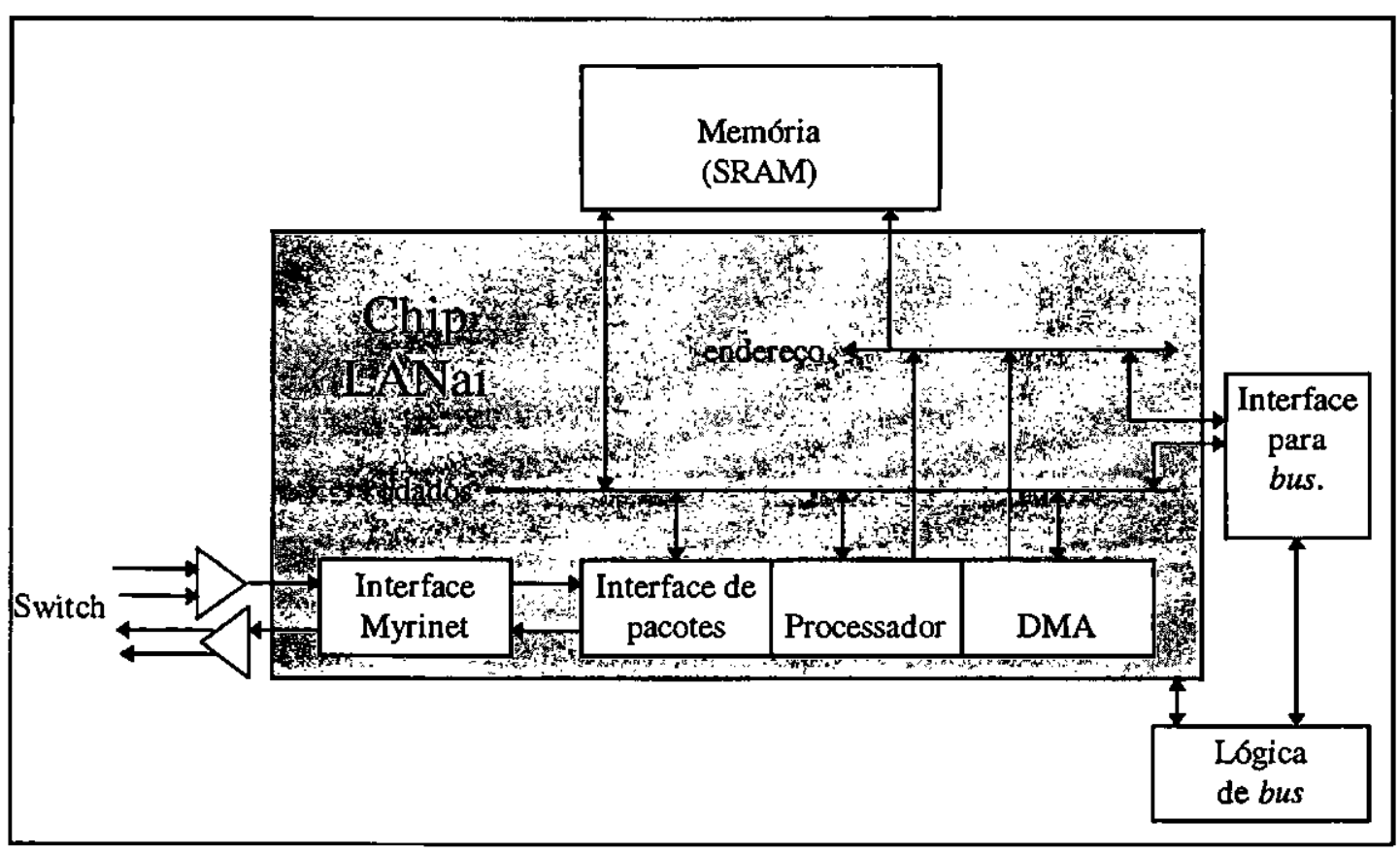

Figura 2-1 Diagrama de uma interface Myrinet

O software para comunicação é composto por um driver instalado na máquina e pelo programa que é executado no processador da placa, chamado de MCP (Myrinet 
Control Program, ou Programa de Controle da Myrinet). Para se ter um bom aproveitamento da velocidade do hardware da Myrinet, seriam necessários sistemas operacionais que deixassem que as interfaces lidassem diretamente com os processos do usuário, sem que houvesse, na transmissão, chaveamento de contexto motivado pela chamada de system calls, checksums do kernel e cópias desnecessárias entre buffers.

Uma versão do TCP/IP que atende esses requisitos foi desenvolvida por pesquisadores da Sun e atingiu uma taxa de $70 \mathrm{Mbps}$ em modelos Sun SPARC-2 com barramento SBUS a $20 \mathrm{MHz}$ [BOD95].

\subsection{Método para análise de sistemas de comunicação}

Os parâmetros para se medir o desempenho de sistemas de comunicação são basicamente a latência (latency) na transmissão e a taxa de transferência (bandwidth) alcançada, já definidos na seção 2.2.3. Esses dois parâmetros podem ter variações significativas considerando-se a forma como são medidos.

Em sistemas de comunicação com diferentes distâncias entre os elementos de processamento, como por exemplo, nos hipercubos, a latência na comunicação entre elementos próximos é menor do que entre elementos distantes. Nesses casos fala-se de uma latência média do sistema, ou seja, mede-se a latência entre elementos com distâncias variadas e calcula-se uma média entre os tempos. Dependendo da aplicação, se a comunicação for mais intensa entre elementos próximos, a latência pode ser menor que a média geralmente apresentada. Um dado freqüentemente apresentado é a latência para pacotes com campo de dados nulo que indica o overhead inicial do sistema de comunicação.

Para altas taxas de transferência, um fator importante é o tamanho dos pacotes das mensagens que estão sendo usados para medi-la. Frequientemente fala-se em taxa de pico, que é a taxa obtida para mensagens de tamanho muito grande (teoricamente de tamanho infinito). Em geral essa taxa é a maior que o sistema pode atingir, mas isso depende da implementação dos protocolos. Em muitos casos, é interessante saber 
a taxa para diferentes tamanhos de pacotes, uma vez que em uma máquina paralela os pacotes tendem a ter tamanho reduzido. $O$ formato da curva indicando as taxas em relação ao tamanho do pacote pode ser mais representativo do que apenas a taxa de pico.

Para mostrar o desempenho da rede apenas com números ao invés de gráficos, um dado importante é o valor $\mathrm{n}_{1 / 2}$. Ele indica o tamanho do pacote, em bytes, que deve ser usado para conseguir uma taxa de transferência que é a metade da taxa de pico do sistema.

Para se determinar os valores dos parâmetros de desempenho mostrados no capítulo seguinte para o protocolo Fast Messages, foram adotados os seguintes critérios de medida [PAK95]:

- Latência: uma mensagem é mandada para um elemento, que a manda de volta à fonte, sendo este procedimento repetido 50 vezes com a mesma mensagem. $O$ tempo total gasto é então dividido pelo número de transmissões para se determinar a latência de 1 transmissão (one-way latency).

- Taxa de transmissão: é medido o tempo para se enviar 65.535 pacotes, sendo dividido o volume de dados enviado pelo tempo gasto.

\subsection{Considerações Finais}

Esse capítulo apresentou os aspectos principais relacionados ao processamento paralelo. Foram discutidas as arquiteturas paralelas, as técnicas para programação paralela e os principais sistemas de passagem de mensagens (PVM e MPI). Foi visto também que uma rede local de computadores pode se transformar em uma máquina paralela virtual. Para um melhor desempenho dessa classe de sistemas é importante que o sistema de comunicação utilizado pelos processos paralelos seja eficiente e não se torne um fator limitante. 


\section{Fast Messages e a Biblioteca Sock2Fm}

Fast Messages (FM) é uma camada de software de alta velocidade para troca de mensagens que proporciona elevada taxa de transferência com baixos tempos de latência para pacotes relativamente pequenos. Em [PAK97b] são descritas implementações de FM para a máquina Cray T3D e para redes Myrinet conectando estações de trabalho Sun. Mais recentemente foram desenvolvidas versões para redes Myrinet e máquinas baseadas em processador Intel Pentium com sistema operacional Windows NT ou Linux [PAK97a].

O objetivo de FM é o de prover uma comunicação eficiente para máquinas paralelas com modelo de passagem de mensagens e também o de proporcionar alta velocidade de comunicação para redes locais de computadores.

\subsection{Características e interface}

O FM provê as seguintes características para as camadas de software acima dele:

- Entrega confiável de pacotes;

- Entrega de pacotes em ordem;

- Ausência de vínculo entre o tipo de processador e o tipo da rede.

A interface de programação do FM versão 1.1 conta com apenas três funções: duas são para o envio de mensagens e uma para o recebimento [PAK97b]. As funções são mostradas na Tabela 3-1. 


\begin{tabular}{|l|l|}
\hline \multicolumn{1}{|c|}{ Função } & \multicolumn{1}{|c|}{ Operação } \\
\hline FM_send(dest, handler, buf, size) & Envia uma mensagem longa. \\
\hline FM_send_4(dest, handler, i0,i1,i2,i3) & $\begin{array}{l}\text { Envia uma mensagem com quatro } \\
\text { palavras. }\end{array}$ \\
\hline FM_extract( ) & Processa mensagens recebidas. \\
\hline
\end{tabular}

\section{Tabela 3-1 API do Fast Messages}

O FM para redes Myrinet está atualmente na versão 2.1 e sua interface sofreu modificações [PAK97a]. Foram incluídas funções para iniciar e terminar o sistema de comunicação, além de diferentes funções para o envio de mensagens. O envio de mensagens agora conta com as funções FM_begin_message, que abre a conexão, e FM_send_piece, que envia por partes a mensagem iniciada com FM_begin_message.

Outra diferença em relação à versão 1.1 é a possibilidade de endereçar mais do que um processo em um mesmo nó de processamento. O FM 2.1 cria para cada interface de rede um número de interfaces lógicas chamadas "contextos". O número de processos por nó fica limitado somente pelo número de contextos disponíveis. A entrada e a saída dinâmica de processos em um programa também estão entre as novidades. Aplicações que necessitem de um modelo de processos dinâmico, como, por exemplo, o modelo cliente-servidor, podem ser implementadas com o FM 2.1.

\subsection{Implementação e desempenho}

O sistema Fast Messages para redes Myrinet foi implementado gradualmente desde seu início com o objetivo de se alcançar alto desempenho de comunicação. A implementação de cada parte envolvida no processamento de seu protocolo teve tratamento apropriado para as características do hardware de comunicação e das máquinas destino. Apesar de tratar de uma versão antiga (1.0) do FM para estações de trabalho Sun, em [PAK95] é demonstrado de forma didática como foi passo a passo a construção do sistema de comunicação. 
A implementação do FM envolveu: a criação de um programa para ser executado no processador das interfaces, a definição da política para transferência de dados entre a memória da máquina e a interface de rede, a forma de gerenciamento de buffers de transmissão e a definição do controle de fluxo associado ao gerenciamento de buffers.

A Figura 3-1 apresenta os gráficos de desempenho de comunicação de uma rede de estações de trabalho Sun conectadas por uma rede Myrinet de 1,28 Gbps. Esses dados representam a versão 1.1 do FM em comparação ao sistema de comunicação proprietário da Myrinet (Myrinet API) [PAK95].
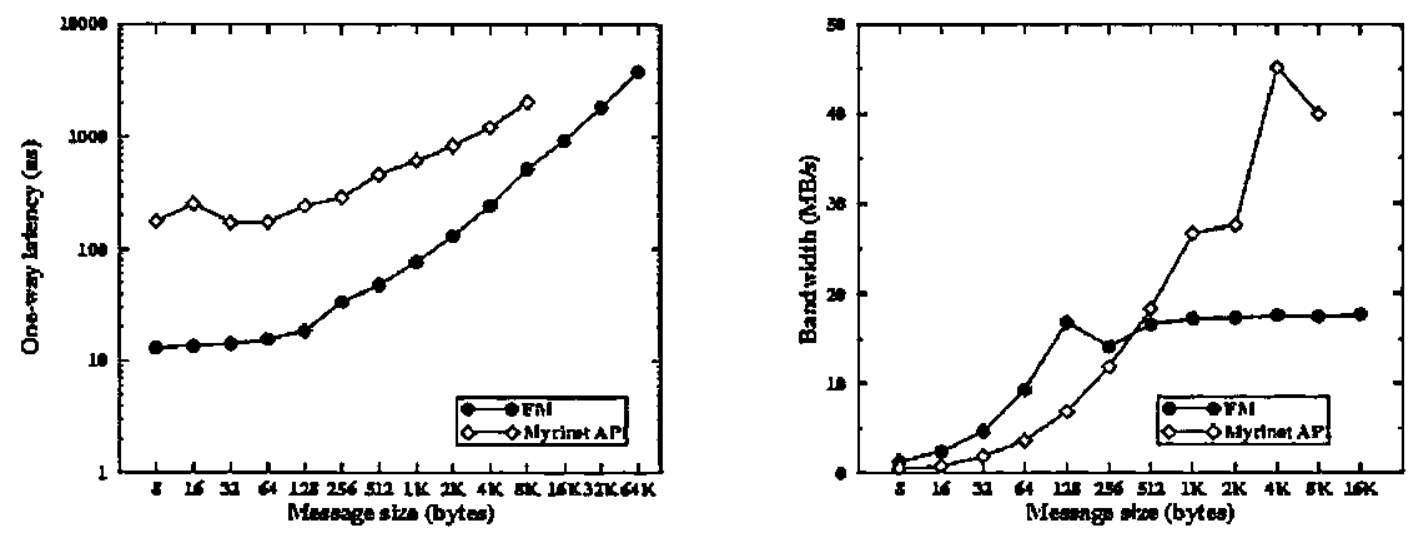

Figura 3-1 desempenho comparativo entrea API FM e a API Myrinet

Pode-se observar que a latência do FM é muito menor para os vários tamanhos de pacotes. Para pacotes pequenos, o FM apresenta uma taxa de transferência maior que o sistema da Myrinet. Para pacotes maiores que aproximadamente 256 bytes, no entanto, o FM é pior devido a forma como foi implementada a transferência entre a memória e a interface. Ao contrário da API Myrinet, o FM usa DMA apenas para transferir dados da interface para a memória, mas não da memória para a interface. Dessa forma foi atingida uma latência menor no envio de pacotes, mas a taxa de transferência sofreu com a velocidade reduzida do barramento Sbus da Sun. No barramento PCI o desempenho do FM (versão 2.1) foi muito superior, apresentando taxa de transferência de pico maior que 77 Mbytes por segundo. 
Na Figura 3-2 [LAU97] é mostrada uma comparação do desempenho de comunicação das bibliotecas MPI das máquinas IBM SP2 e Cray T3D em relação a uma versão de MPI sobre Fast Messages em máquinas Sun.
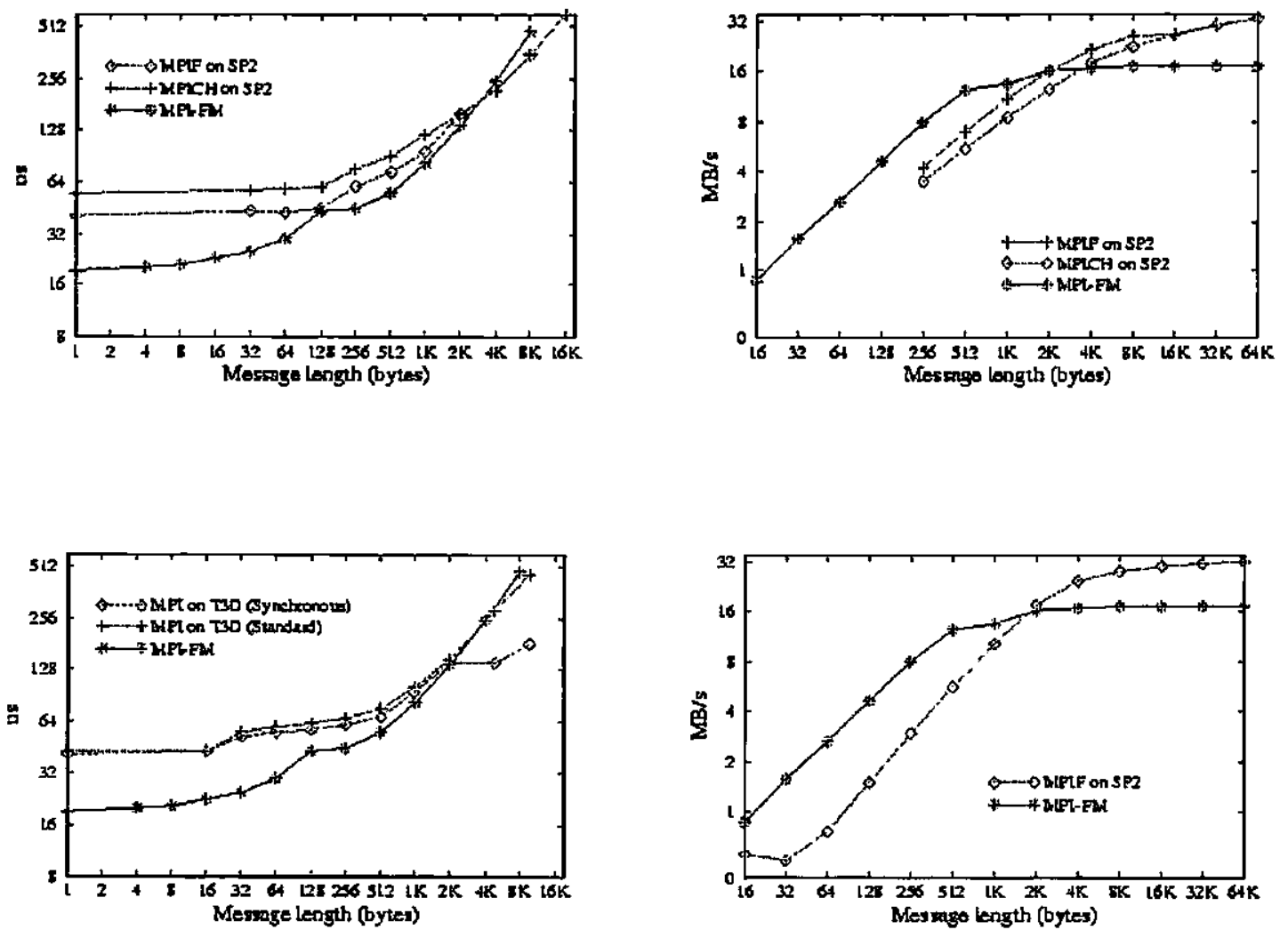

latência

taxa de transferência

Figura 3-2 Comparação de desempenho de MPI entre o IBM SP2, Cray T3D e sobre rede Myrinet

Para pacotes de até 2 Kbytes, o sistema FM mostra um desempenho superior em ambos os casos, comprovando sua eficácia na síntese de arquiteturas paralelas utilizando redes de computadores. 


\subsection{HPVM}

Com o objetivo de proporcionar computação de alto desempenho com hardware de baixo custo, pesquisadores da Universidade de Illinois (EUA) desenvolveram um pacote denominado HPVM (High Performance Virtual Machines) [PAK97a]. A máquina alvo para HPVM é composta por conjuntos de processadores Pentium conectados por uma rede de comunicação Myricom Myrinet [MYR98] de alta velocidade, executando os sistemas operacionais Linux ou Windows NT. O HPVM oferece ao programador as interfaces MPI, SHMEM, Global Arrays e Fast Messages para o desenvolvimento de aplicações paralelas [PAK97a].

Também está prevista uma versão de HPF (High Performance Fortran) que será incluída no pacote HPVM, aumentando o leque de possibilidades para o programador. A Figura 3-1 mostra a organização em camadas do sistema HPVM como ele está hoje.

\begin{tabular}{|c|c|c|c|}
\hline \multicolumn{4}{|c|}{ Aplicações } \\
\hline MPI & SHMEM & $\begin{array}{l}\text { Global } \\
\text { Arrays }\end{array}$ & \\
\hline \multicolumn{4}{|c|}{ Fast Messages } \\
\hline & & & sockets \\
\hline & Myrinet & & Ethernet \\
\hline
\end{tabular}

\section{Figura 3-1 Camadas do HPVM}

O sistema Fast Messages (FM) é uma camada de baixo nível com alto desempenho para troca de mensagens, como foi visto na última seção, e sobre a qual todas as outras interfaces do HPVM residem [CHI97]. Ele foi desenvolvido com o objetivo de ser utilizado em uma ampla gama de plataformas e ser a base para a construção de camadas de troca de mensagens em mais alto nível. O FM define um conjunto básico de primitivas de comunicação ponto-a-ponto e delega a responsabilidade de prover características mais avançadas às camadas acima dele. 
Como se pode ver na Figura 3-1, o usuário tem acesso à API do FM, podendo programar diretamente sem passar pelas outras camadas.

Um dos principais problemas de protocolos de comunicação como o TCP/IP é o alto overhead que o software introduz na comunicação [KAR94]. Esse overhead não é viável numa rede de comunicação interna de uma máquina paralela, sendo nesse caso interessante o uso de FM, que tem a característica de fornecer às aplicações velocidades próximas à velocidade da camada física da rede [PAK97b].

O HPVM contém duas implementações de cada uma de suas interfaces: uma para alto desempenho e outra mais lenta para desenvolvimento. Todas as API's são idênticas para as duas versões do software. A implementação para alto desempenho requer a instalação de uma rede Myrinet; a de desenvolvimento usa sockets [COM91] e pode ser executada em qualquer rede que tenha essa interface (TCP/IP). A versão para sockets tem um overhead muito maior que a versão para a Myrinet. Por exemplo, a latência na transferência de uma mensagem em Fast Messages sobre Myrinet é da ordem de 10 microsegundos, enquanto que na versão sockets sobre Ethernet a $10 \mathrm{Mbps}$ a latência atinge 650 microsegundos [PAK97a].

Uma versão da biblioteca MPI sobre Fast Messages para redes Myrinet conectando estações de trabalho da Sun Microsystems foi adaptada e incorporada no pacote HPVM como parte do trabalho de mestrado de Mario Lauria [LAU96], um pesquisador italiano da Universidade de Nápoles. Seu trabalho foi desenvolvido na Universidade de Illinois, e teve a intenção de demonstrar que é possível obter-se com uma rede de computadores desempenho de comunicação alto o suficiente no nível de aplicação para competir com os MPPs (Massively Parallel Processors).

\subsection{Programando com Fast Messages}

Para que processos possam se comunicar através da biblioteca Fast Messages versão 2.1 que acompanha o pacote HPVM, é necessário antes iniciar o sistema no máquina paralela. Um dos nós deve executar o "Global Manager", que é um daemon 
que controla a comunicação em toda a máquina. Em cada nó onde haverão processos comunicantes, deve-se executar o "Context Manager", indicando através de uma variável de ambiente qual é o nome do nó que será o "Global Manager". Esses daemons são necessários para se gerenciar, entre outras coisas, a identificação dos processos e a declaração de handlers que são associados às mensagens.

Um handler é uma função escrita pelo usuário que fará o recebimento do pacote. $\mathrm{O}$ processo que envia uma mensagem associa a ela um handler para que 0 processo que está recebendo saiba qual função de recebimento tratará esta mensagem. A declaração de um handler tem a forma:

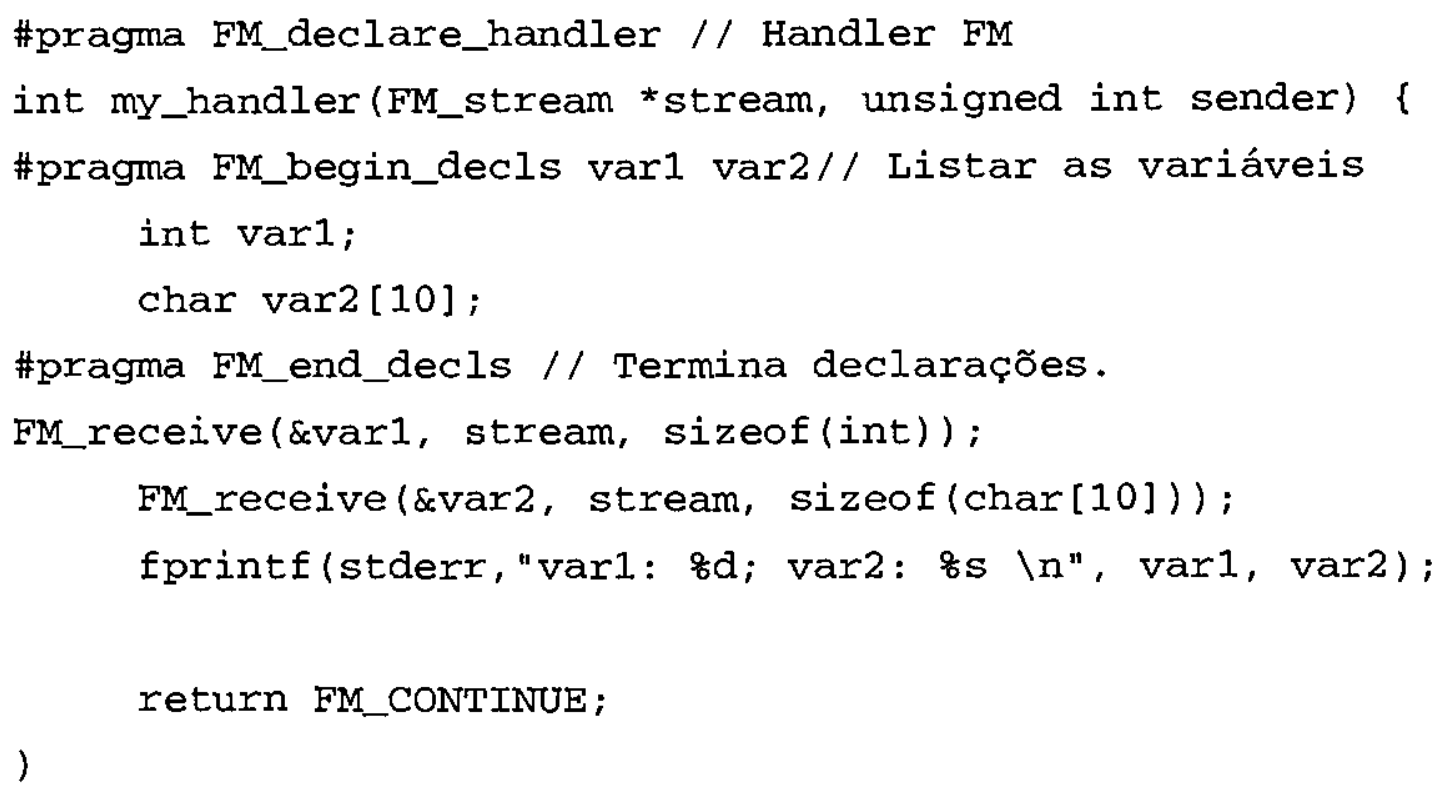

A biblioteca Fast Messages conta com poucas funções disponíveis ao usuário na sua interface. São elas:

- FM_set_parameter( ): usada para estabelecer um parâmetro utilizado na iniciação, como por exemplo FM_QUIET, que elimina as mensagens que a biblioteca imprime;

- FM_initialize( ): chamada para iniciar as estruturas de dados locais do processo, inserir o processo no gerenciador de comunicação local da máquina através de comunicaçāo com o "Context Manager" e no cluster através de comunicação com o "Global Manager". Inicia as variáveis FM_nodeid (número de identificação do processo) e FM_numnodes 
(número de processos que entraram no programa até o momento) que são visíveis pelo usuário;

- FM_register_handler( ): associa um handler a uma função que realiza o recebimento de pacotes.

- FM_reallocate_credit( ): redimensiona as janelas de recebimento do controle de fluxo de acordo com o número de processos participantes do programa no momento. Isso melhora o desempenho da rede;

- FM_finalize( ): libera as estruturas iniciadas com FM_initialize( );

- FM_begin_message( ): retorna um stream para comunicação com um certo processo (cujo identificador é indicado) e um certo handler. $\mathrm{O}$ stream é usado pela função FM_send_piece( );

- FM_send_piece( ): envia dados para um stream que foi determinada por FM_begin_message( );

- FM_end_message( ): termina o envio de uma mensagem que havia sido iniciada por FM_begin_message( );

- FM_extract( ): extrai pacotes da rede e envia à função associada ao handler da mensagem;

- FM_receive( ): recebe dados de um stream. Deve ser chamada apenas dentro de uma função associada a um handler.

Pode-se observar que, diferentemente de sockets, Fast Messages não possui o conceito de conexão a portas de acesso (IP + porta) para iniciar uma comunicação. Os processos são endereçados diretamente através do seu identificador e as mensagens são tratadas pela função handler associada.

\subsection{Implementação do projeto}


A biblioteca desenvolvida para servir de interface entre os aplicativos do usuário e o sistema Fast Messages sobre Myrinet recebeu o nome de "Sock2fm". A Figura 3-1 mostra as camadas do sistema de comunicação ao se usar Sock2fm.

Para cada função da API sockets foi criada uma função corresponde na biblioteca "sock2fm", como por exemplo connect() que se transformou em fm_connect().

\begin{tabular}{|c|}
\hline Software do usuário \\
\hline Sock2fm \\
\hline Fast Messages \\
\hline Rede física Myrinet \\
\hline
\end{tabular}

\section{Figura 3-1 Camadas do sistema de comunicação com Sock2Fm}

No desenvolvimento da biblioteca "sock2fm", foi abordado inicialmente o problema da associação de um socket a uma porta. Em sockets, o processo que vai aguardar comunicação realiza um bind() entre um descritor socket $\mathrm{e}$ o número de uma porta. Se o protocolo for TCP, o processo que quer se comunicar com o outro processo realiza um connect() de um descritor socket seu ao IP e à porta que o primeiro processo estabeleceu. O mecanismo pelo qual o segundo processo sabe qual é a porta, depende da aplicação. A porta pode ser uma porta padrão fixa, como a porta 21 para FTP ou 80 para HTTP, ou ser atribuída dinamicamente pelo sistema.Em Fast Messages não existe esse tipo de mecanismo. Para solucionar esse problema, optou-se pela criação de um daemon "Servidor de Bind". Quando é chamada no código do usuário a função $f m_{-}$bind(), ela pede para o servidor armazenar seu IP e a porta que ela deseja divulgar, assim como o identificador de comunicação desse processo. $\mathrm{Na}$ tentativa de $f m_{\text {connect() }}$ ) de outro processo àquela porta, este processo requisitante pergunta primeiro ao servidor qual é o identificador do processo que responde pela porta. Descobrindo qual é o identificador, é feita então a negociação de descritores de 
comunicação entre os dois processos, no caso de simulação de TCP, ou então, no caso de UDP, aquele que chamou fm_connect() preenche a estrutura do descritor de comunicação local com as informações provenientes do "Servidor de Bind".

No caso de simulação do protocolo TCP, o processo que divulgou a porta recebe os pedidos de conexão e os guarda em uma fila de recebimento. Somente quando este processo executar um fm_accept() é que os pedidos serão atendidos. Isso é necessário porque o mecanismo connect/accept não é síncrono. Além disso, o fm_accept() só bloqueia o processamento e espera conexões se não houverem pedidos em espera.

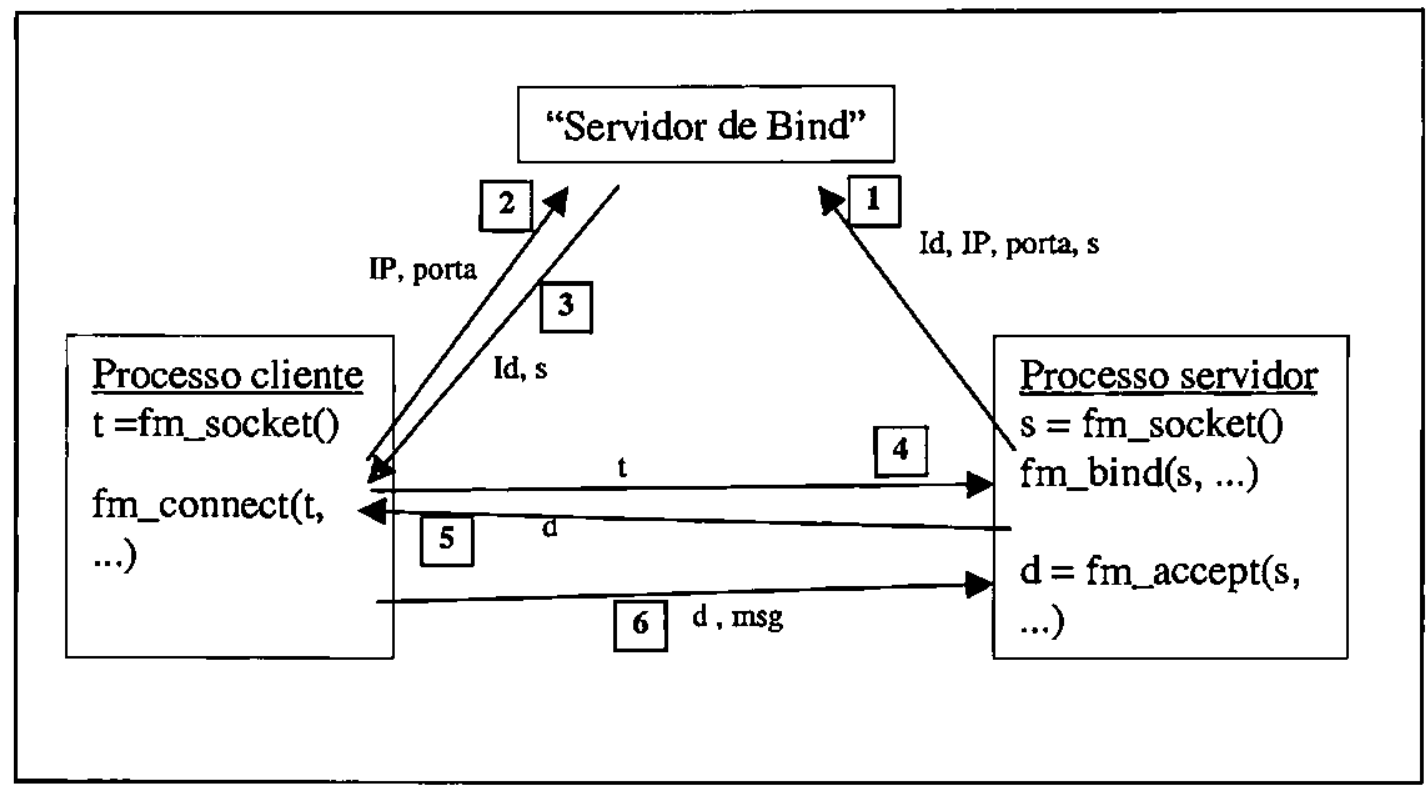

Figura 3-2 Exemplo de conexão para protocolo conectado tipo TCP

A Figura 3-2 mostra o mecanismo de accept/connect no protocolo tipo TCP. As setas indicam a comunicação entre os processos, sendo que os números associados a elas indicam a ordem em que ocorrem essas comunicações. Os parâmetros associados são enviados na mensagem. Depois de conectados, os processos podem enviar mensagens diretamente um para o outro através dos descritores de comunicação negociados. O custo adicional (overhead) de comunicação com o "Servidor de Bind" somente acontece na conexão. 
Como o mecanismo de write/read também não é síncrono, foi implementada uma estrutura de dados para os descritores de comunicação que inclui uma fila para armazenamento de mensagens que chegam. O fm_write() não bloqueia o processamento. Ele envia a mensagem ou para o handler "readH" que foi definido para tratar as mensagens de protocolo conectado (tipo TCP) ou para o handler "recvfromH", que foi definido para mensagens tipo UDP. Esses handlers lidam com a mensagem inserindo-a na fila de recebimento do descritor apropriado. Apenas quando o processo que recebeu a mensagem realiza um $f m_{-}$read() ou um $f m_{-} r e c v f r o m()$ é que a mensagem é retirada da fila e processada pelo programa do usuário. Assim como no caso do $f m \_a c c e p t()$, o $f m \_r e a d()$ ou $f m \_r e c v f r o m()$ só bloqueiam se a fila estiver vazia.

Alguns dos handlers definidos são os seguintes:

- acceptH e connectH: usados na negociação envolvida no mecanismo de connect/accept no protocolo tipo TCP. São relacionados com as funções $f m \_a c c e p t()$ e $f m_{-}$connect(). O fm_connect() envia mensagem para o acceptH e o fm_accept() envia retorno para o connectH;

- readH e recvfromH: recebem os pacotes e entregam ao descritor apropriado. fm_write() e fm_sendto() enviam mensagens para esses handlers;

- transH e transretH: usados na comunicação com o "Servidor de Bind". Esse servidor recebe pedidos pelo handler transH e retorna enviando mensagem para o transretH do processo requisitante. O servidor atende pedidos de inserção e pesquisa com um mecanismo tipo RPC.

\subsection{Otimizações para maiores ganhos de desempenho}

Os primeiros testes de desempenho da biblioteca Sock $2 \mathrm{fm}$ apresentaram um desempenho muito abaixo do esperado. Para vários tamanhos de pacote enviados, a taxa de transferência não passava de 100 Kbytes por segundo. Esses valores se demonstraram baixíssimos se comparados com o potencial declarado de mais de 600 
Mbits por segundo (75 Mbytes/s) em modo half-duplex, utilizando-se comunicação entre duas máquinas apenas (usando apenas uma das duas chaves internas que compõem o switch Myrinet utilizado nos testes).

Quando a biblioteca foi desenvolvida não se pôde avaliar esse problema de desempenho, uma vez que para o desenvolvimento foi utilizada a versão de baixo desempenho do sistema Fast Messages, que usa na verdade TCP/IP em baixo nível. Isso foi necessário por não se ter disponível naquele momento a rede Myrinet.

\subsubsection{Buffers na interface de rede}

Depois de um estudo da situação, se constatou que a origem do problema poderia ser o gerenciamento de buffers internos na interface de rede que o sistema Fast Messages estava realizando.

Fast Messages é muito conservador na alocação de buffers na placa para os processos de recebimento de mensagens que estão se comunicando se não for definido o número de processos comunicantes. Os espaços alocados são pequenos por não se saber quantos processos vão receber dados via Fast Messages. Para resolver esse problema, a API de Fast Messages conta com uma função chamada FM_reallocate_credit(), que redimensiona as janelas de recebimento do controle de fluxo do protocolo de acordo com o número de processos participantes do programa no momento, melhorando o desempenho da rede.

Para se utilizar FM_reallocate_credit() na biblioteca Sock2fm foram escolhidas as funções fm_accept() e fm_connect. $O$ instante em que ocorre uma negociação de conexão entre dois processos é um momento apropriado para se recalcular o tamanho dos buffers de recebimento porque a conexão pode vir de um processo novo que acabou de entrar no sistema. Então para cada processo novo que quer utilizar Sock2fm (e indiretamente Fast Messages) ocorre novamente o cálculo de espaço da memória na placa.

Com isso, houve um aumento imediato de desempenho. O desempenho de Sock2fm superou o desempenho da biblioteca sockets padrão e TCP/IP na Myrinet para pacotes acima de 250 bytes. Essa foi a primeira modificação inserida na 
biblioteca na busca por melhor desempenho. Outras duas mudanças maiores ainda foram introduzidas, antes de se medir o desempenho contido na Tabela 4-1 e na Figura 4-1.

\subsubsection{Armazenamento de mensagens em listas encadeadas}

A segunda modificação na biblioteca foi a introdução de listas encadeadas para recebimento de mensagens e armazenamento nas estruturas dos descritores de comunicação. Quando um processo envia uma mensagem a outro com fm_write(), por exemplo, o processo que recebe a mensagem deve armazenar o pacote numa fila de recebimento relacionada com o descritor definido pelo processo que envia. $O$ pacote fica na fila até o momento em que o programa do usuário realiza um fm_read() naquele descritor.

Na primeira versão de Sock2fm, esse fila era implementada com "pipes" do sistema operacional, criados com a system call pipe(). Isso não era apropriado por ser necessária a utilização das system calls write() e read() para se escrever e ler dados no pipe. Chamadas a system calls são relativamente lentas e introduzem um overhead não aceitável num sistema de comunicação de alto desempenho.

Foi decidida então a implementação dessas filas com o uso de listas encadeadas, tendo sido criadas funções para o gerenciamento das listas. Dessa forma, os dados recebidos por um processo são tratados por código que reside unicamente no espaço de programa do usuário, sem o desvio de controle para o sistema operacional.

\subsubsection{Recebimento de mensagens diretamente em espaço do usuário}

A terceira mudança na biblioteca foi relativa a forma como os pacotes de dados são tratados quando chegam ao processo destino. Na primeira versão, quando uma mensagem era recebida por Sock $2 \mathrm{fm}$ ela era imediatamente inserida na fila de recebimento para posterior leitura pelo programa do usuário com o uso, por exemplo, de fm_read(). Se o programa já estivesse bloqueado esperando por uma mensagem o 
processo era exatamente o mesmo, ou seja, a mensagem era inserida na fila e imediatamente retirada da fila.

Com a modificação, se o processo já estiver bloqueado esperando por pacotes, o pacote que chega não é inserido na fila, e sim copiado diretamente para a porção de memória que o usuário definiu na chamada da função de leitura. Se o processo chegar a ponto de bloquear, significa que ele já leu todos os dados que estavam ma fila de recepção e ainda está aguardando por mais. Dessa forma, quando o pacote chega, a fila está vazia e o pacote é copiado diretamente na área de memória do usuário.

Isso garante uma economia de tempo na recepção de dados. Evitando o armazenamento de pacotes na fila, economiza-se as chamadas de função para inserção e remoção da fila e também se economiza uma cópia d os dados da memória do sistema Fast Messages para a fila. 


\section{Testes de desempenho}

A rede Myrinet usada nos testes de desempenho é composta de oito placas de interface com barramento PCI e um switch de oito portas, além dos cabos de conexão e da fonte de alimentação do switch.

A rede foi instalada inicialmente ligando-se dois computadores Pentium II, um de $333 \mathrm{MHz}$ e um de $400 \mathrm{MHz}$, o primeiro com 256 Mbytes de memória e o segundo com 64 Mbytes de memória. Ambos os computadores continham o sistema operacional Linux, o primeiro com distribuição Slackware 3.6, o segundo com Red Hat 5.1 e ambos com kemel 2.0.35. Para a rede funcionar no Linux, é necessária a inclusão do módulo apropriado no kemel, contendo o driver das placas de comunicação Myrinet.

Os arquivos usados na instalação para que a rede Myrinet funcione com os protocolos e APIs desenvolvidos pela Myricom, fabricante de Myrinet, podern ser encontrados no site da empresa na Internet em www.myri.com. Para se utilizar a rede com o sistema Fast Messages, um módulo diferente deve ser inserido no kemel. Os arquivos de instalação do sistema Fast Messages podem ser encontrados em wwwcsag.cs.uiuc.edu.

Com a rede instalada e configurada, foram criados programas de benchmark para se medir o desempenho da rede em TCP-UDP/IP e Fast Messages. Foram criados

programas tipo cliente/servidor para UDP e TCP e programas que enviam dados com as primitivas de Fast Messages.

\subsection{Desempenho de Sock2Fm}

O desempenho atingido por Sock2fm, comparado com sockets padrão em TCP/IP na Myrinet, é apresentado na Tabela 4-1 e na Figura 4-1.

Para se testar o desempenho da biblioteca, foram criados dois programas que enviam mensagens um para o outro, determinando-se a taxa de transferência efetiva 
(incluindo a latência) do sistema de comunicação. Os mesmos programas foram convertidos para a biblioteca sockets normal (sobre TCP/IP) para se comparar os resultados obtidos.

A latência pode ser estimada enviando-se pacotes de tamanho zero bytes, e $e$ calculada dividindo-se o tempo gasto na transmissão pelo número de pacotes enviados. Deve-se observar que a taxa de transferência considera apenas os dados úteis transferidos pela rede, ou seja, $\varepsilon$ a taxa que a aplicação do usuário vai efetivamente ter disponível. Os bytes dos headers (cabeçalhos) inseridos pelos protocolos não são calculados, pois isso acarretaria num desempenho maior que o obtido, mas que não é atingido pela aplicação do usuário.

A Tabela 4-1 mostra os valores obtidos, enviando-se 65000 mensagens para se obter um valor médio.

\begin{tabular}{|c|c|c|}
\hline $\begin{array}{c}\text { Tamanho da } \\
\text { mensagem } \\
\text { (bytes) }\end{array}$ & $\begin{array}{c}\text { Sock2fm } \\
\text { (Mbytes/s) }\end{array}$ & $\begin{array}{c}\text { TCP/IP - Myrinet } \\
\text { (Mbytes/s) }\end{array}$ \\
\cline { 2 - 3 } & 1.28 & 1.33 \\
\hline 10 & 5.50 & 5.83 \\
\hline 50 & 9.21 & 10.67 \\
\hline 100 & 15.61 & 14.79 \\
\hline 250 & 21.63 & 18.98 \\
\hline 500 & 31.27 & 19.07 \\
\hline 1000 & 32.56 & 19.60 \\
\hline 5000 & 33.84 & 19.63 \\
\hline 10000 & 35.37 & 20.49 \\
\hline 20000 & 36.00 & 20.14 \\
\hline 50000 & & \\
\hline
\end{tabular}

Tabela 4-1 desempenho comparativo entre Sock2Fm e TCP/IP na Myrinet

Em pacotes de até aproximadamente 250 bytes, o TCP/IP mostra um desempenho levemente superior. A taxa de transferência de TCP/IP para pacotes de 10 bytes é $4 \%$ maior que a da biblioteca Sock $2 \mathrm{fm}$. Para pacotes maiores que 250 bytes 
a situação se inverte, chegando a uma superioridade de $64 \%$ de Sock $2 \mathrm{fm}$ para pacotes de 1.000 bytes e $79 \%$ para pacotes de 50.000 bytes.

Um programa que envia mensagens usando a biblioteca Fast Messages diretamente foi testado para que se pudesse determinar o overhead que Sock $2 \mathrm{fm}$ impõe. Para pacotes de 10 bytes, a taxa de transferência desse programa resultou em 2,23 Mbytes/s. No extremo oposto, em pacotes de 50.000 bytes, a taxa foi de 53 Mbytes/s. A latência de TCP/IP resultou em apenas 1,78 microssegundos, enquanto Sock2fm atingiu 7,58 microssegundos e Fast Messages 4,30 microssegundos. Sock $2 \mathrm{fm}$ apresentou um desempenho de aproximadamente metade do desempenho obtido com Fast Messages diretamente. Isso se explica pelo fato de que a biblioteca Sock2fm, ao receber um pacote, realiza duas chamadas de função e em muitos casos uma cópia de buffer a mais. As chamadas são para a função fm_read() e a função chamada no handler para inserir a mensagem na fila de recep̧ão. A cópia de buffer extra se dá quando ocorre a extração do pacote e sua escrita na fila, quando for necessária. Operações de cópia de buffer, principalmente, devem ser evitadas em protocolos de comunicação quando possível, por exigirem muito processamento.

No gráfico da Figura 4-1 pode-se ver os valores contidos na Tabela 4-1:

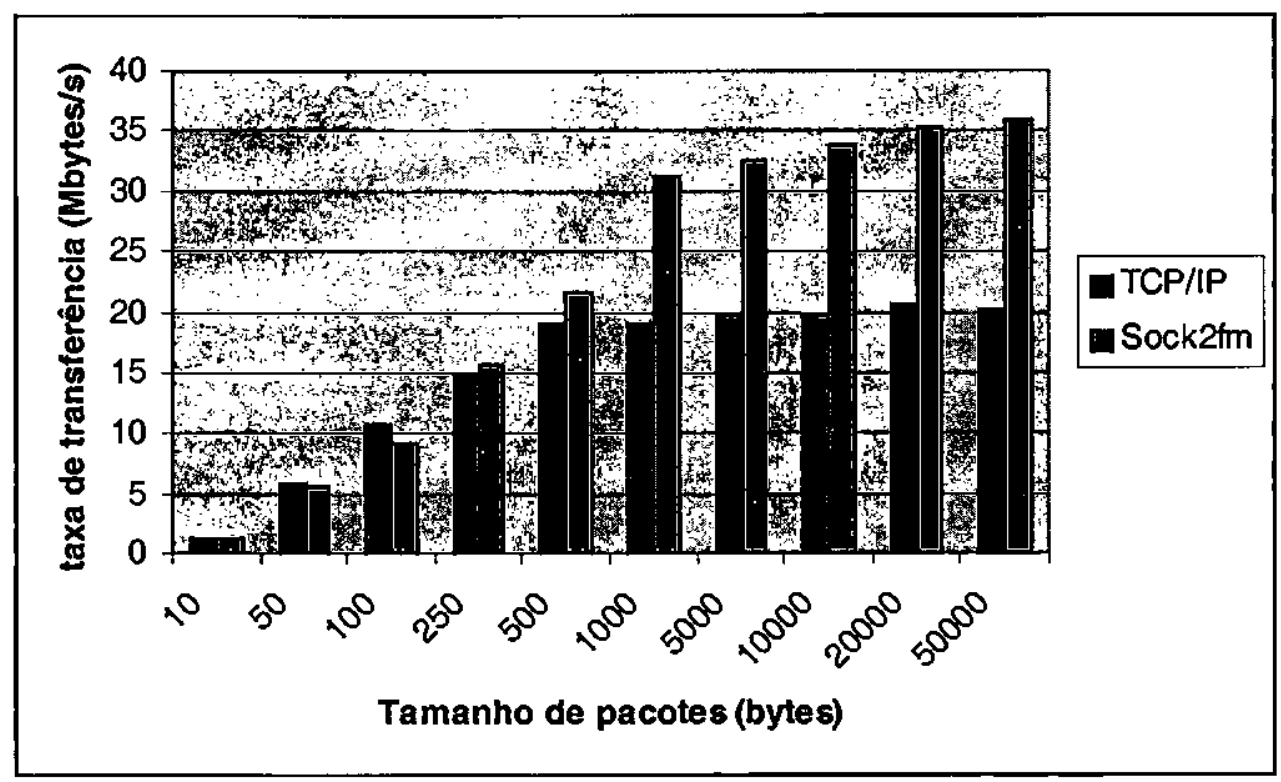

Figura 4-1 desempenho comparativo de TCP/IP e Sock2fm em rede Myrinet 


\subsection{Análise de desempenho de PVM sobre TCPMP}

Para os testes de desempenho apresentados a seguir foram utilizadas duas máquinas Pentium II, sendo uma com $350 \mathrm{MHz}$ e a outra com $400 \mathrm{MHz}$ de clock. Ambas as máquinas possuiam 64 Mbytes de memória e sistema operacional Linux com distribuição Red Hat 5.2 e kernel 2.0.36.

Três redes interligam os computadores: uma Ethernet a $10 \mathrm{Mbps}$, uma Fast Ethernet a 100 Mbps e a rede Myrinet com seus declarados 2,56 Gigabits por segundo de taxa de transferência agregada.

Antes de se testar o desempenho de PVM, foi aferido o desempenho do protocolo TCP/IP para as três redes citadas. Os primeiros testes realizados utilizaram TCP/IP através da API sockets para se determinar a taxa de transferência para vários tamanhos de pacotes. Foram testadas, nas três redes, as taxas de transferência para pacotes de $10,50,100,250,500,1.000,5.000,10.000,20.000$ e 50.000 bytes. Os resultados são mostrados na Tabela 4-1 e na Figura 4-1.

\begin{tabular}{|c|c|c|c|}
\hline $\begin{array}{c}\text { Tamanho } \\
\text { (bytes) }\end{array}$ & \multicolumn{3}{|c|}{$\begin{array}{c}\text { Taxa de transferência em } \\
\text { TPC/IP (Mbytes/s) }\end{array}$} \\
\hline & Myri & Fast Eth & Eth \\
\hline 10 & 1,37 & 1,64 & 0,92 \\
\hline 50 & 6,07 & 6,69 & 0,95 \\
\hline 100 & 10,95 & 8,70 & 0,96 \\
\hline 250 & 19,71 & 9,50 & 0,91 \\
\hline 500 & 20,45 & 9,77 & 0,95 \\
\hline 1000 & 20,48 & 9,84 & 0,94 \\
\hline 5000 & 20,91 & 9,87 & 0,92 \\
\hline 10000 & 21,17 & 9,95 & 0,92 \\
\hline 20000 & 21,82 & 10,01 & 0,91 \\
\hline 50000 & 21,86 & 10,02 & 0,90 \\
\hline
\end{tabular}

Tabela 4-1 Taxa de transferência para sockets padrão

Para pacotes com menos de 100 bytes, Fast Ethernet mostrou um desempenho melhor que a rede Myrinet para TCP/IP. A situação se inverte para pacotes maiores, 
com a Myrinet chegando a atingir mais que o dobro da taxa de transferência de Fast Ethernet para pacotes acima de 250 bytes. Os valores para a Ethernet a $10 \mathrm{Mbps}$ foram bastante inferiores, mas para todos os tamanhos de pacote ela atingiu uma taxa uniforme e próxima de sua taxa máxima declarada, que é de 1,25 Mbytes por segundo (10 Mbits por segundo divididos por 8 bits que formam 1 byte). Fast Ethernet também chegou próxima de sua taxa máxima, que é de 12,5 Mbytes por segundo, para pacotes acima de 250 bytes.

Já a rede Myrinet, tendo atingido 21,86 Mbytes por segundo no máximo para os pacotes testados, se mostrou pouco eficiente se considerarmos que sua taxa máxima declarada é de aproximadamente $75 \mathrm{Mbytes}$ por segundo em half-duplex. Isso demonstra que TCP/IP não é o protocolo mais adequado para se tirar toda a potência de comunicação que a rede Myrinet oferece. A taxa de transferência obtida utilizandose o sistema Fast Messages diretamente chegou a atingir 53 Mbytes por segundo e se mostra muito mais compatível com a velocidade física da rede.

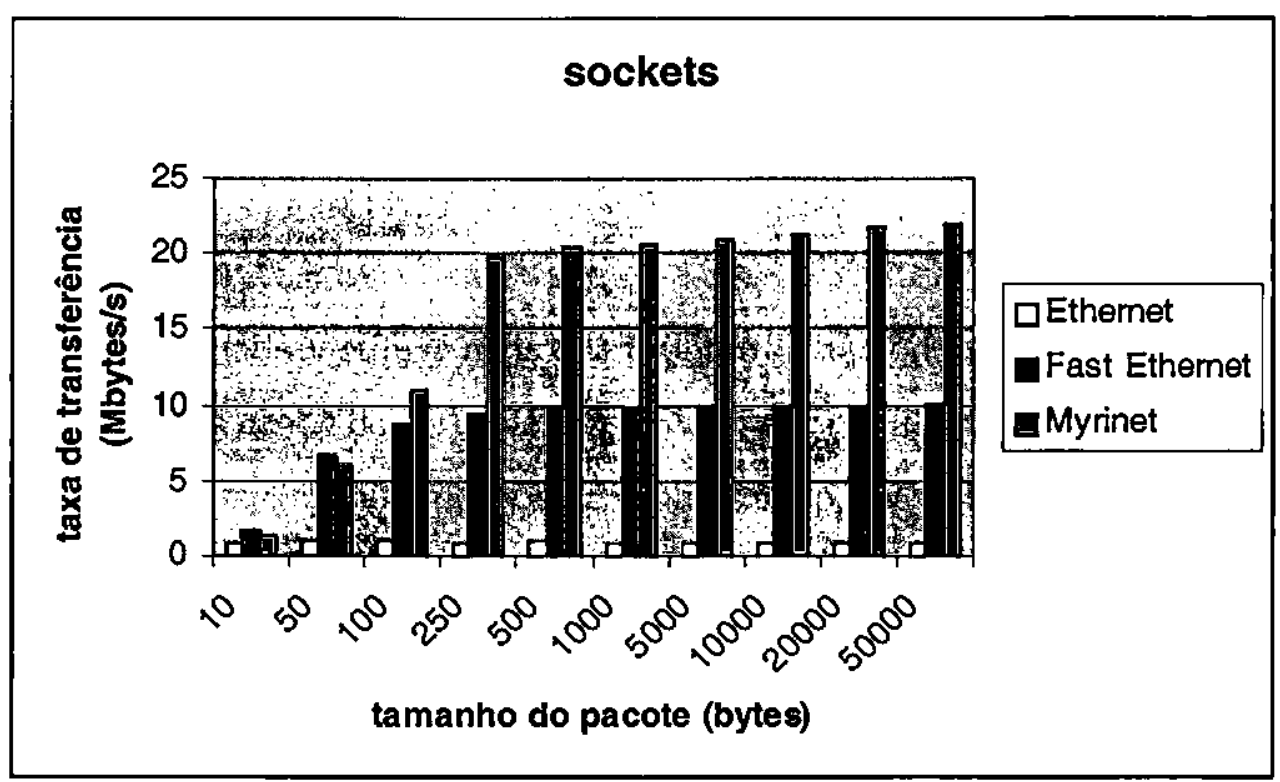

Figura 4-1 Taxa de transferência para sockets padrão

Em seguida, foram realizadas medições de desempenho nas três redes com o sistema PVM. Os programas desenvolvidos utilizavam formatação de dados raw para o envio da mensagem, ou seja, sem formatação, através de uma opção de programação. Isso garante um menor gasto de tempo no processamento do pacote para 
o envio. Também foi utilizada a opção de roteamento direto de pacotes, sem passar pelo daemon, que garante um desempenho melhor em comunicação quando se têm poucos processos comunicantes.

Para pacotes de até 500 bytes aproximadamente, todas as redes tiveram uma taxa de transferência muito baixa se comparada com os valores obtidos com sockets diretamente. A Myrinet, por exemplo, atingiu apenas 2 Kbytes por segundo em pacotes de 10 bytes. Quanto maiores os pacotes testados, melhor foi o desempenho da rede. Isso mostra que o sistema PVM acrescenta um overhead muito grande de comunicação.

A Tabela 4-2 apresenta os valores obtidos nos testes.

\begin{tabular}{|c|c|c|c|}
\hline $\begin{array}{c}\text { Tamanho } \\
\text { (bytes) }\end{array}$ & \multicolumn{3}{|c|}{$\begin{array}{c}\text { Taxa de transferência em } \\
\text { PVM (Mbytes/s) }\end{array}$} \\
\hline & Myri & Fast Eth & Eth \\
\hline 10 & 0,0020 & 0,0042 & 0,0042 \\
\hline 50 & 0,0096 & 0,0214 & 0,0214 \\
\hline 100 & 0,0190 & 0,0427 & 0,0428 \\
\hline 250 & 0,0477 & 0,1069 & 0,1070 \\
\hline 500 & 0,0955 & 0,4245 & 0,4009 \\
\hline 1000 & 0,1908 & 9,0148 & 0,9925 \\
\hline 5000 & 0,7155 & 9,6105 & 1,0141 \\
\hline 10000 & 9,1350 & 9,7863 & 1,0379 \\
\hline 20000 & 9,8920 & 10,0597 & 1,0489 \\
\hline 50000 & 8,8973 & 9,4409 & 1,0381 \\
\hline
\end{tabular}

Tabela 4-2 Taxa de transferência para PVM sobre TCP/IP

A primeira descoberta surpreendente foi o fraco desempenho de PVM na Myrinet quando comparado com Fast Ethernet. Para todos os pacotes testados Fast Ethernet se mostrou superior. A diferença para pacotes com aproximadamente 1.000 bytes foi muito grande, com uma taxa na rede Fast Ethernet cerca de 45 vezes maior que na rede Myrinet. A diferença diminuiu para pacotes acima de 5.000 bytes.

Outro fato que deve ser observado foi a equivalência de valores entre Ethernet e Fast Ethernet para pacotes de até 500 bytes. Acima disso, Fast Ethernet sofre um salto em desempenho, superando a Ethernet. 
Tanto na rede Myrinet quanto na Fast Ethernet foi notado um salto em desempenho a partir de um certo tamanho de pacote. Foi investigado o tamanho dos pacotes em que ocorria o fenômeno e descobriu-se que na Myrinet o tamanho situa-se entre 5.800 e 5.900 bytes, enquanto que em Fast Ethernet o salto de deu entre $800 \mathrm{e}$ 900 bytes. Esse fato está relacionado provavelmente com a forma que PVM gerencia seus buffers de transmissão e retransmissão de pacotes.

Os dados da Tabela 4-2 foram divididos e apresentados em dois gráficos para melhor visualização. A Figura 4-2 mostra a taxa para os tamanhos de pacotes entre 10 e 500 bytes, enquanto a Figura 4-3 mostra os pacotes entre 1.000 e 50.000 bytes.

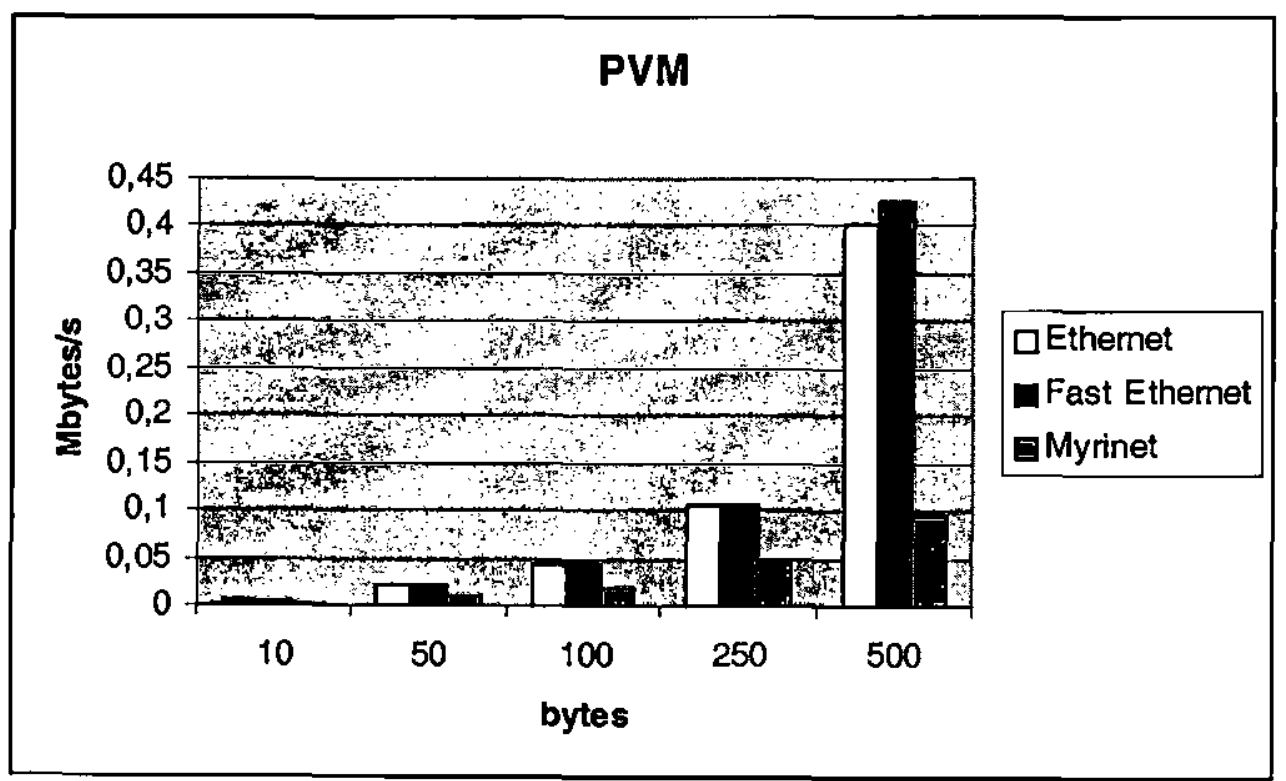

Figura 4-2 Taxa de PVM para pacotes entre 10 e 500 bytes 


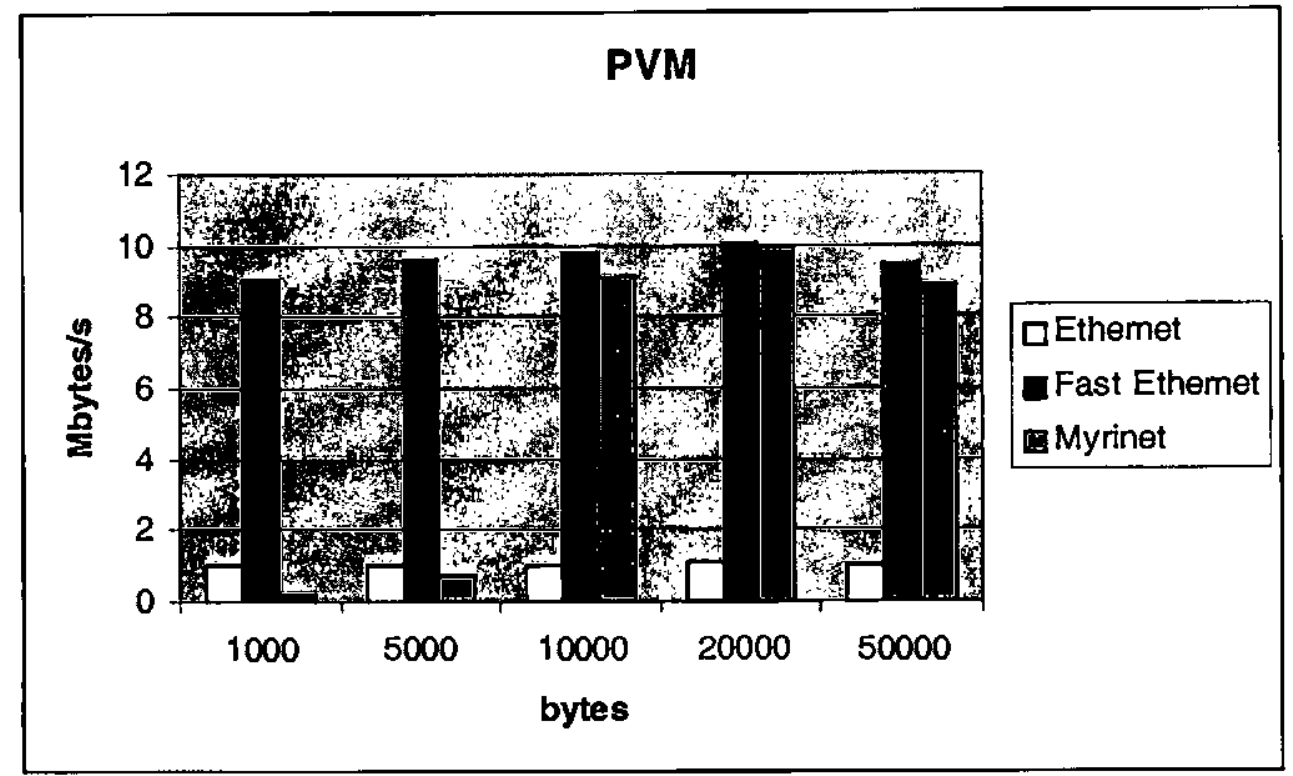

Figura 4-3 Taxa de PVM para pacotes entre 1.000 e 50.000 bytes 


\section{Conclusões}

O processamento paralelo tem se tornado uma realidade possível pelo baixo custo das redes de comunicação de dados e de processadores de alto desempenho que podem trabalhar em conjunto como uma arquitetura paralela. Esses sistemas apresentam uma relação custo/benefício bastante favorável em relação a máquinas mais poderosas e caras que têm sido usadas para aplicações de grande porte.

Tornando-se mais fácil o acesso ao hardware, uma nova gama de aplicações mais comuns pode surgir fazendo uso do processamento paralelo, surgindo também a necessidade de software básico para o desenvolvimento e execução de aplicações nessa classe de arquiteturas.

Para se aproveitar todo o potencial do hardware das redes de comunicação atuais, é necessário que também o software evolua e proporcione aos programadores de aplicações paralelas o desempenho que é esperado da rede.

O PVM é um sistema muito utilizado para programação paralela e uma versão de alto desempenho para redes de computadores pessoais pode expandir seu uso. A busca por velocidade de comunicação em máquinas paralelas baseadas em redes de computadores é de grande interesse na comunidade científica. Uma versão de PVM com alto desempenho de comunicação executando em uma máquina paralela de baixo custo vem de encontro a esse grande interesse na comunidade científica e de centros comerciais que necessitem um maior poder computacional. O PVM é um sistema muito utilizado proporcionado aplicações altamente portáveis, que podem ser executadas em uma grande quantidade de plataformas.

Esse trabalho mostrou que os baixos valores apresentados pelo PVM sobre TCP/IP em redes Myrinet reforça a tese de que é necessária uma plataforma de comunicação mais eficaz para se obter um melhor desempenho da rede física Myrinet. O sistema PVM utilizando comunicação baseada em Fast Messages deve apresentar 
um desempenho geral melhor do que PVM-TPC/IP demonstrou, como já indicam os testes da biblioteca Sock2fm em comparação com sockets-TCP/IP.

O custo de uma rede Myrinet hoje, em tomo de 10 a 15 vezes maior que um sistema com Fast Ethernet para a máquina paralela SPP2 (8 processadores), não se justifica se o sistema de comunicação utilizado for PVM sobre TCP/IP. A vantagem que a Myrinet teria vem do fato de ser possível a comunicação entre vários pares de processos ao mesmo tempo pela rede, uma vez que a rede é baseada em switch. Mas essa vantagem depende da aplicação paralela desenvolvida pelo usuário utilizar eficientemente o recurso. Além disso, uma rede Fast Ethernet também pode utilizar um switch eliminando-se a desvantagem da utilização de hubs repetidores.

\section{Trabalhos futuros}

A evolução natural do projeto é o desenvolvimento de uma versão do sistema de passagem de mensagens PVM que utilize a biblioteca Sock2Fm, desenvolvida nesse trabalho de mestrado.

Com a máquina paralela SPP3 contando com uma rede Myrinet de alto desempenho e uma versão de PVM que utilize Fast Messages em baixo nível para comunicação pode-se determinar em aplicações paralelas reais qual é o ganho de desempenho dessa plataforma em relação ao PVM padrão sobre TCP/IP.

O desenvolvimento de programas para medições de desempenho (benchmarks) mais elaborados e que utilizem uma grande quantidade de processos e processadores podem também ser usados nessa plataforma, sendo que esses mesmos benchmarks podem ser aplicados em outras plataformas para comparação, uma vez que PVM possui versões para a maioria das plataformas existentes no mercado. 


\section{Apêndice A - Comunicação no PVM padrão}

A distribuição do PVM padrão, disponível na Internet, pode ser encontrada para várias plataformas comerciais, necessitando apenas ser compilada para a máquina destino desejada. Entre essas plataformas está incluída uma versão para o sistema operacional Linux em processadores da linha Intel. $O$ software possui aproximadamente 50.000 linhas de código em linguagem $\mathrm{C}$ distribuídas entre mais de 70 arquivos.

No sistema PVM ocorre a troca de mensagens entre os Pvmd's (PVM daemons), entre Pvmd e tasks (processos paralelos que se comunicam através do PVM) e entre dois tasks. Na comunicação Pvmd-Pvmd é utilizado protocolo UDP. UDP provê comunicação não confiável e não orientada a conexão. Pacotes podem ser perdidos, duplicados e chegarem em ordem errada, mas o PVM utiliza um mecanismo de confirmação e retransmissão. TCP poderia ter sido usado, mas UDP foi preferido por alguns fatores.

Em primeiro lugar, cada Pvmd deve se comunicar com todos os outros Pvmd's. Dessa forma, se fosse utilizado TCP, os Pvmd's deveriam possuir um file descriptor aberto para cada outro Pvmd, ou seja, $\mathrm{N}-1$ para uma máquina virtual com $\mathrm{N}$ máquinas. Isso e um fator limitante, pois algumas máquinas possuem um limite para "file descriptors" abertos. Com UDP, um único descritor pode ser usado para comunicar com os outros Pvmd's. Em segundo lugar vem o overhead que TCP acarretaria na iniciação da máquina virtual. O mecanismo de accept( )/connect( ), que envolve comunicação, deveria ser feito de cada Pvmd para os outros Pvmd's. Com UDP a iniciação ocorre sem comunicação.

Na comunicação Pvmd-tasks e task-task é utilizado protocolo TCP por proporcionar comunicação confiável, livrando os tasks de fazerem retransmissões de pacotes se UDP fosse utilizado, já que TCP se encarrega disso. 


\section{Apêndice B - O SPP3}

O SPP3 é uma arquitetura paralela MIMD com memória distribuída que segue a tendência da maioria das arquiteturas MIMD com memória distribuída disponíveis no mercado, ou seja, a utilização de microcomputadores interligados por uma rede de comunicação de alto desempenho. Cada no pode ser composto por placas com até 4 processadores e memória compartilhada. Quando somos usados nós com mais de um processador, o sistema operacional fica encarregado da distribuição de processos e balanceamento de carga entre os processadores. A utilização de mais de um processador por no faz da arquitetura do SPP3 uma arquitetura MIMD híbrida, utilizando ao mesmo tempo os paradigmas de programação de memória compartilhada e memória distribuída. É possível utilizar placas de processadores Pentium Intel, DEC Alpha ou PowerPC. Na verdade, o único requisito para o processador é que seja disponível para ele uma versão do sistema operacional Linux. Atualmente, dependendo da placa utilizada, a memória pode atingir mais de 1 Gbyte por processador. A figura B-1 apresenta uma visão geral da arquitetura do SPP3.

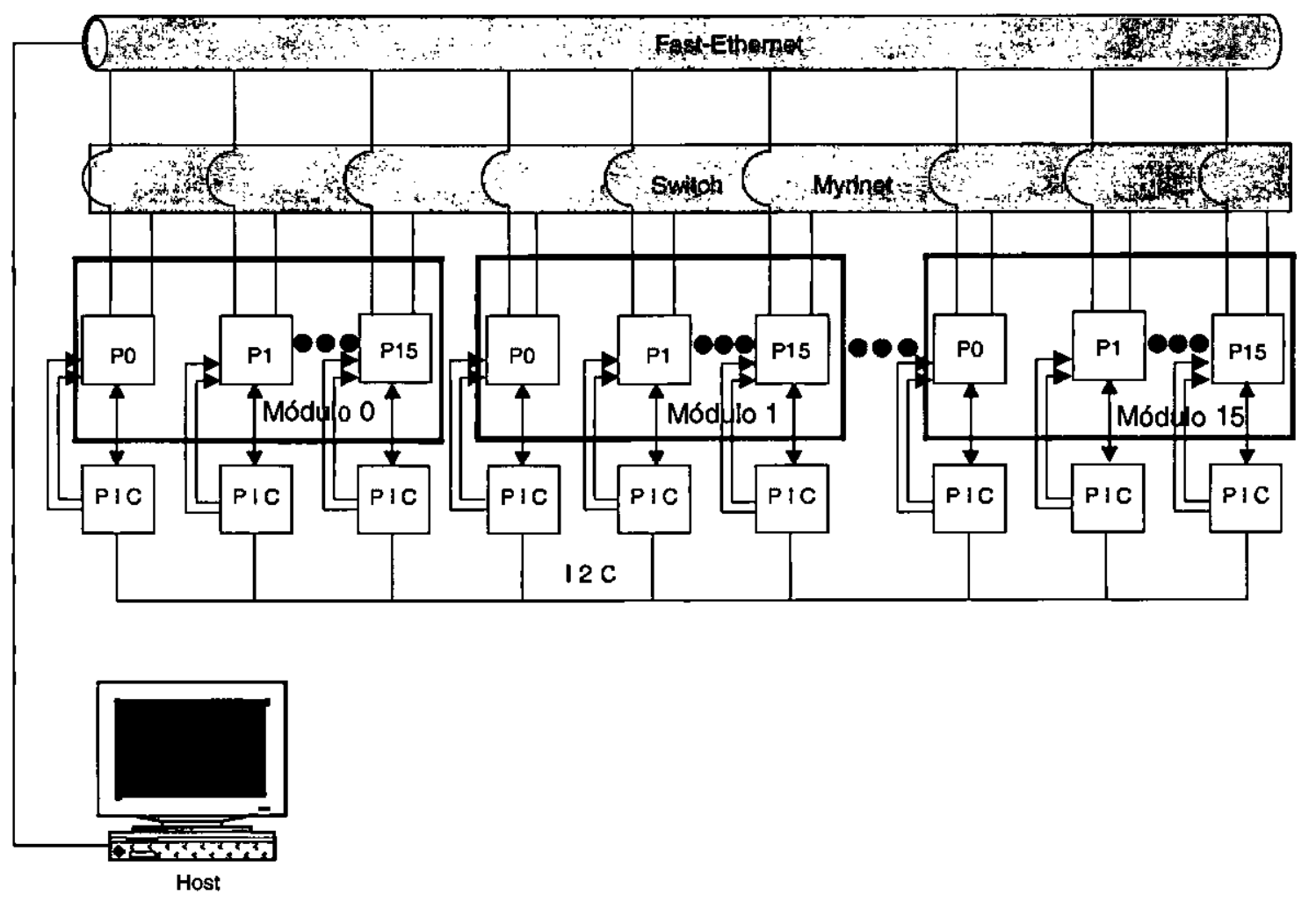

B-1 Arquitetura do SPP3 
A arquitetura do SPP3 é escalável podendo chegar até 256 nós processadores (PN00.00 a PN15.15) distribuídos em módulos de 16 processadores cada um. Uma máquina com um único módulo pode conter até 32 processadores. Os processadores são interligados por três redes de comunicação: uma rede Fast-Ethernet, utilizada para o controle e gerenciamento do sistema, uma rede para comunicação de dados de alto desempenho, a Myrinet, e, uma terceira rede específica para controle e monitoração do sistema que é baseada nos microcontroladores PIC e no barramento I2C (Inter Integrated Circuit bus).

A rede I2C possibilita a monitoração e controle dos nós do SPP3, tal como a reiniciação física de um processador e controle liga-desliga. A figura B-2 ilustra a interação entre a rede de controle $\mathrm{I} 2 \mathrm{C}$ e um dos nós do sistema.

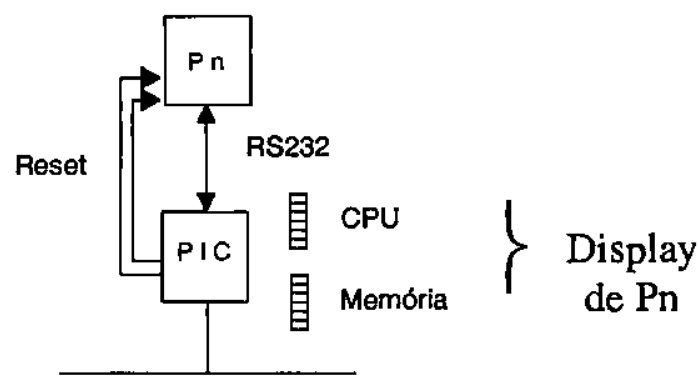

\section{B-2 Rede I2C no SPP3}

O nó de processamento $(\mathrm{Pn})$ pode enviar comandos ao microcontrolador (PIC) através de uma interface serial RS232, possibilitando a um nó comandar o reset físico de outro nó inoperante na rede. $O$ display utiliza dois gráficos para indicar a utilização de memória e CPU do nó.

O host tem a função de servidor de arquivos e servidor de boot remoto. Opcionalmente, cada nó pode ter seu disco local, o que torna mais ágil o armazenamento e acesso de dados individuais dos processos de cada nó. A área de memória swap, nesse último caso, pode ser local em contraposição ao caso de nós sem disco cuja área de swap reside no host.

Os nós do SPP3 dispõem de processadores Intel da linha Pentium II e executam o sistema operacional Linux - que tem se mostrado bastante confiável e impõe uma carga computacional leve ao processador em relação a outros sistemas operacionais disponíveis, tais como o Windows NT e outras versões de UNIX. Os 
processadores Intel têm apresentado um desempenho compatível com os melhores processadores do mercado.

Apesar do SPP3 ser configurado fisicamente em um único gabinete, ele pode ter a configuração física tradicional de uma rede local de computadores. 
Referências e bibliografia

[ALM94] ALMASI, G.S.; GOTTLIEB, A. Highly parallel computing. 2.ed. The Benjamin Cummings Publishing Company, Inc., 1994.

[BOD95] BODEN, N. J.; COHEN,D.; FELDERMAN, R. E.; KULAVIK, A. E.; SEITZ, C. L.; SU, W. K. Myrinet, a Gigabit per second local-area network. IEEE Micro (15), 1995.

[CHI94] CHIEN, A.; KONSTANTINIDOU, M. Workioads and performance metrics for evaiuating parailel interconnects. IEEE TCCA (newsletter), 1994.

[CHI97] CHIEN, A.; PAKIN, S.; LAURIA, M; BUCHANAN, M; HANE, K.; GIANNINI, L.; PRUSAKOVA, J. High Performance Virtual Machines (HPVM): Clusters with Supercomputing APIs and Performance. Eighth SIAM Conference on Parallel Processing for Scientific Computing (PP97). Março, 1997.

[COM91] COMER, D. E. Internetworking with TCP/IP - Principles, Protocois and Architeture. Prentice Hall, vol. 1, 1991.

[DES87] DESROCHERS, G. R.. Principles of parallel and multiprocessing. McGraw-Hill, 1987.

[DUN90] DUNCAN, R. A survey of parallel computer architectures. IEEE Comput. Mag., v. 23, Fevereiro 1990.

[FOS95] FOSTER, I. Designing and building parallel programs: concepts and toois for parallel software engineering. Addison-Wesley Publishing Company Inc., 1995.

[GEI94] GEIST, G.A.; BEGUELIN, A.; DONGARRA, J.; JIANG, W.; 
MANCHECK, R., SUNDERAM, V. PVM : Parallel Virtual Machine - A user's guide and tutorial for networked parallel computing. The MIT Press, 1994.

[GEl96] GEIST, G.A.; KOHL, J.A.; PAPADOPOULUS, P.M. PVM and MPi: a Comparison of Features. Calculateurs Paralleles, Vol. 8, No. 2, 1996

[HWA93] HWANG, K. Advanced computer architecture: parailelism, scalability, programmability. MacGraw-Hill, Inc., 1993.

[KAR94] KARAMCHETI, V.; CHIEN, A. Software Overhead in Messaging Layers: Where Does The Time Go? Architectural Support of Programming Languages and Operating Systems (ASPLOS-VI), 1994.

[LAU96] LAURIA, M. High Performance MPI Implementation on a Network of Workstations. Dissertação de Mestrado, Universidade de lllinois, Urbana, 1996.

[LAU97] LAURIA, M.; CHIEN, A. MPI-FM: High Performance MPI on Workstation Clusters. Journal of Parallel and Distributed Computing, Janeiro, 1997.

[LIN98] LDP - LINUX Documentation Project , manuais do sistema operacional Linux, www.sunsite.unc.edu, 1998.

[LIU95] LIU, L. T.; CULLER, D. E. Evaluation of the Intel Paragon on Active Message Comunication. Proceedings of Intel Supercomputer Users Group Conference. Junho, 1995.

[LIU94] LIU, L. T.; CULLER, D. E. Measurements of Active Messages Performance on the CM-5. Relatório Técnico, University of California at Berkeley. Maio, 1994

[MYR98] www.myri.com, site da empresa Myricom na Internet. 
[NAV89] NAVAUX, P.O.A. Introdução ao processamento paralelo. RBC- Revista Brasileira de Computação, v. 5, n. 2, p.31-43, Outubro 1989.

[PAK95] PAKIN, S.; LAURIA, M.; CHIEN, A. High Performance Messaging on Workstations: Illinois Fast Messages (FM) for Myrinet. Supercomputing'95, San Diego, California.

[PAK97a] PAKIN, S.; BUCHANAN, M.; CONNELLY, K.; LAVERY, A.; KOENING, G.; GIANNINI, L.; PRUSAKOVA, J.; HERMANN, G.; CHIEN, A. HPVM 1.0 User Documentatlon. Documentação inclusa no pacote HPVM, disponivel em http://wwwcsag.cs.uiuc.edu/ projects/hpvm.html, 1997.

[PAK97b] PAKIN, S.; KARAMCHETI, V.; CHIEN, A. Fast Messages(FM): Efficient, Portable Communication for Workstation Clusters and Massiveiy-Parallel Processors. IEEE Concurrency, 1997.

[PAT90] PATTERSON, D. A.; HENNESSY, J. L. Computer architecture: a quantitative approach. Morgan Kaufmann Publishers, Inc., 1990.

[SNI96] SNIR, M.; OTTO, S.; HUSS-LEDERMAN, S.; WALKER, D.; DONGARRA, J. MPI: The complete Reference. The MIT Press, 1996.

[TAN92] TANENBAUM, A.S. Modern operating systems. 2.ed., Prentice Hall International Inc., 1992.

[TAN96] TANENBAUM, A. S. Computer Networks. 3.ed., Prentice Hall International Inc, 1996.

[TRI95a] TRINDADE, O.; MARQUES, E.; JEUKENS, I. A parallel archltecture based on personal computers - requirements and definitions. In: Simpósio Nipo-Brasileiro de Ciência e Tecnologia, p. 203-212, Agosto 1995. 
[TRI95b] TRINDADE, O., MARQUES, E., JEUKENS, I., A parallel architecture based on personal computers - requirements and definitions - an overview. In: XV International Conference of the Chilean Computer Society, p. 479-490, Novembro 1995. 


\section{Errata}

Página 64: onde se lê "na Tabela 4-1 e na Figura 4-1" leia-se "na Tabela 4-2 e na Figura 4-2". No título da tabela, leia-se "Tabela 4-2".

Página 65: Leia-se "Figura 4-2" no título da figura.

Página 66: Leia-se "Tabela 4-3" onde se lê "Tabela 4-2".

Página 67: onde se lê "Tabela 4-2" leia-se "Tabela 4-3". Onde se lê "Figura 4-2" leia-se "Figura 4-3" e onde se lê "Figura 4-3" leia-se "Figura 4-4".

Página 68: onde se lê "Figura 4-3" leia-se "Figura 4-4". 